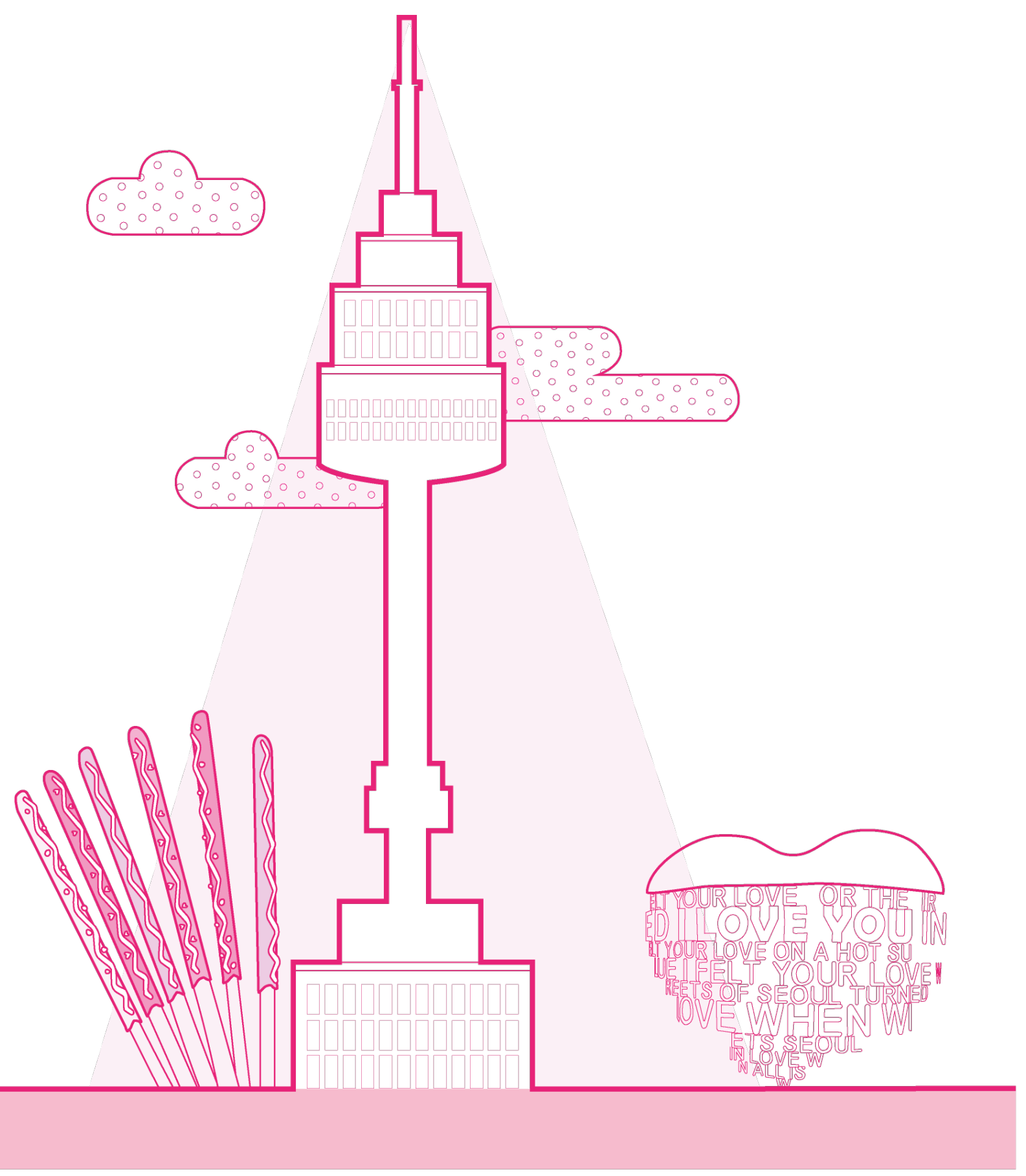

\title{
The city of Bang:
}

The transformation of privacy in Seoul.

FINAL DISSERTATION

Nuria Martínez Martínez

Tutor. Miguel Mesa del Castillo Clavel 


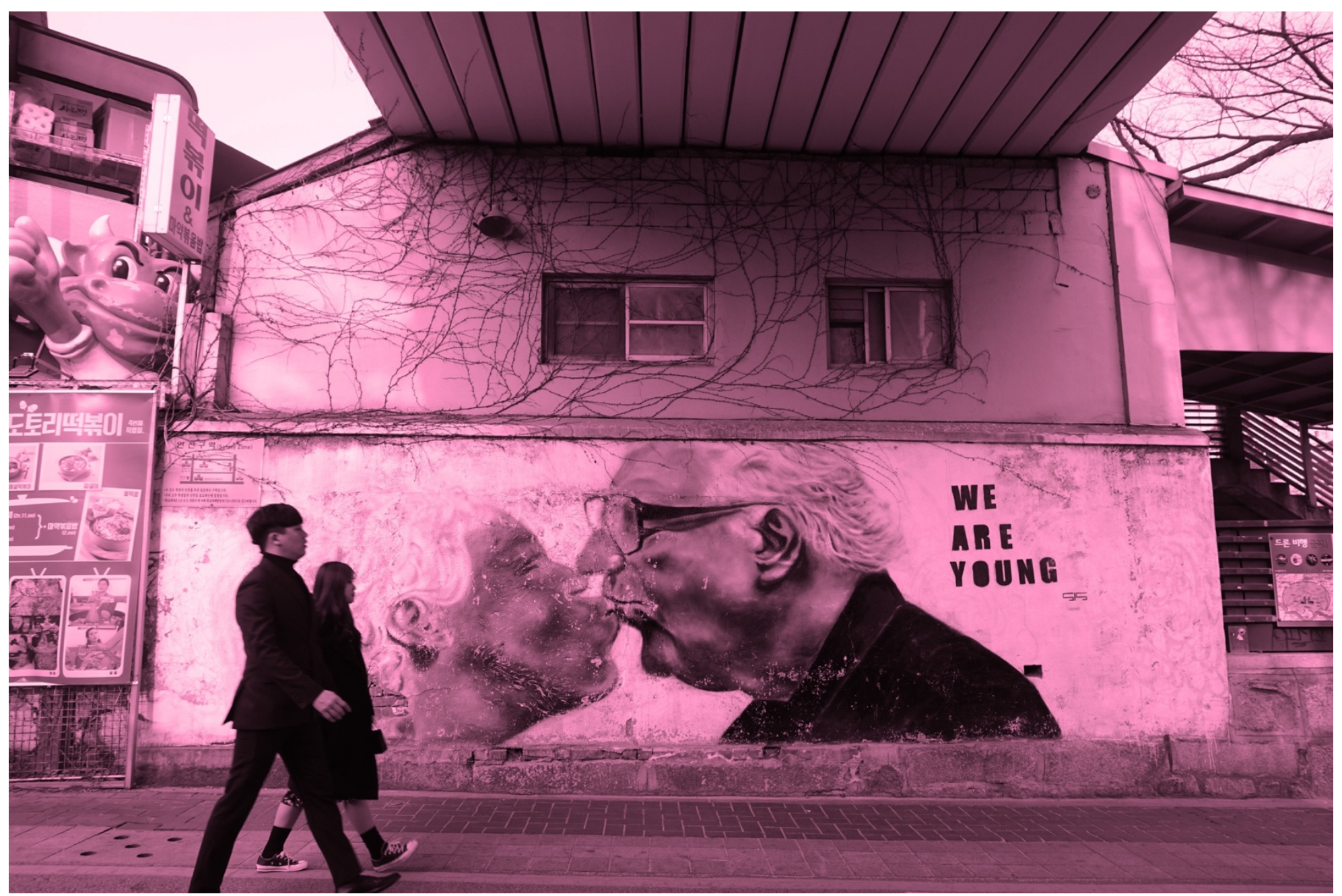

Figurw 1: 26th March, 2017. Graffitti in Bukchon Hanok Village. 


\section{//Abstract//}

Seoul is one of the most connected and one of the fastest cities in the world when it comes to transformation. Like any contemporary city, Seoul allows people to abandon the scale conception imposed by urbanism, and thanks to its equipment of connection tools, it allows us to construct identities through a complex process, in which both the controversy and disparity of Korean culture are introduced as building values.

This is how the "Bang" is born; one of the manifestations of hybrid public spaces, domestic but at the same time commercial, that serves as an extension of the private space. A useful took from which to equip the ways of building society. Bangs exist thanks to the multiple geographic, technological and social conjunctures, connecting the population, technology and space.

The Bang as a mediation model; whose reading and reassembly will make it a useful tool for the construction of the contemporary city. 

To those who have had to watch the moon for nine months, While I already smelled like coffee in the Seoul underground.

To those who have had to endure my absence at its best, And for that, I will regret for a long time.

To those who have been a gift of architecture, Because I wish to share this path for many more years with them.

To those who have been able to keep hopes of moving forward, And theirs to teach and give me the opportunity to guide me on this journey. 


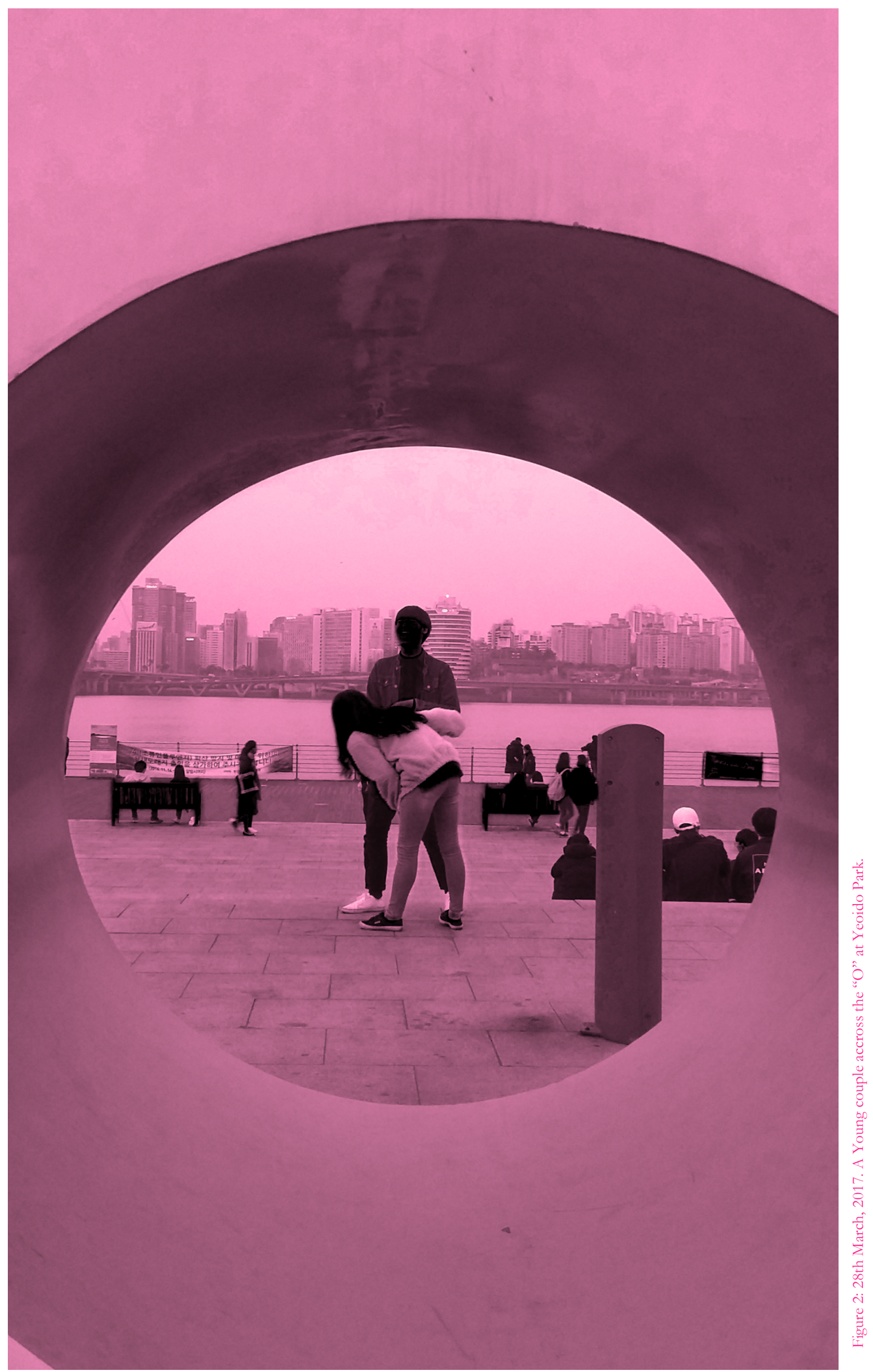




\section{-/TABLE OF CONTENTS/-}

\section{INTRODUCTIÓN}

// Background......................................2//

//Trigger......................................... $4 / /$

2. The CITY: Seoul

//Objetives.............................................6//

//Descriptions....................................8//

- Economic Context -

- Political and Social Context -

- Genre and Power -

\section{BANG and the CITY}

+DVD Bang//DVD Room.......................42 +

+ Norae Bang //Karaoke..........................52 +

+ Motel//Love Hotel...............................58 +

4. CONCLUSIONS

$/ / \ldots \ldots 66 \ldots . . / /$

5. REFERENCES

$/ / \ldots \ldots 68 \ldots . . / /$ 


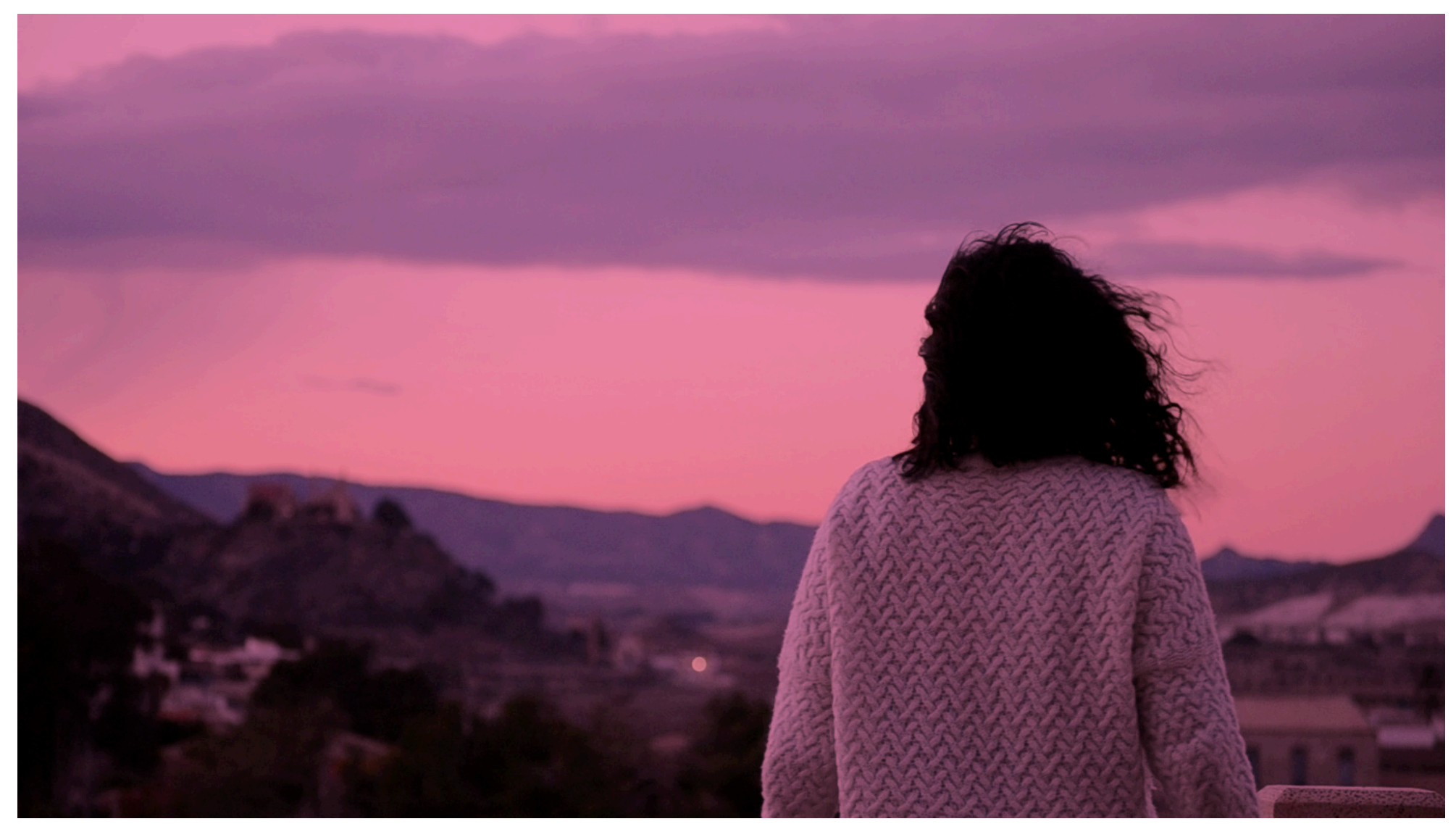

Figure 3: 13th February, 2015. Views from my window to the sactuary of my hometown, called Novelda. 


\title{
1. Introduction
}

\author{
/ /Background/ /
}

Dear Reader, my name is Nuria Martínez Martínez. WELCOME. I am 25 years old, and I study architecture at the University of Alicante. I am the eldest of two sibling. My parents are still happily married, and I live with them in a small town called Novelda. At least I have lived there 23 years of my live.

A year ago I decided to leave my home, not thinking that would end up being the search for a topic for this academic work, which formalizes the end of a stage, and in turn, "represents" my personal and professional beginning in the world of architecture. Although it could be said that the topic that is developed in the next pages was the one to find me, and I thank for it.

The following represents a personal and emotional journey, through architectural interests, with the restlessness and curiosity necessary to study the issues of a vertiginous present that we face and which I would not like to qualify as irregular. It only depends on our capacity to have learnt from error.

It should be said that the elaboration of this final dissertation is not only understood as an end-of-cycle document, but also as an investigation that shapes the beginning of an adventure that may be longer, and which could present its continuation in a final scholarly thesis. 


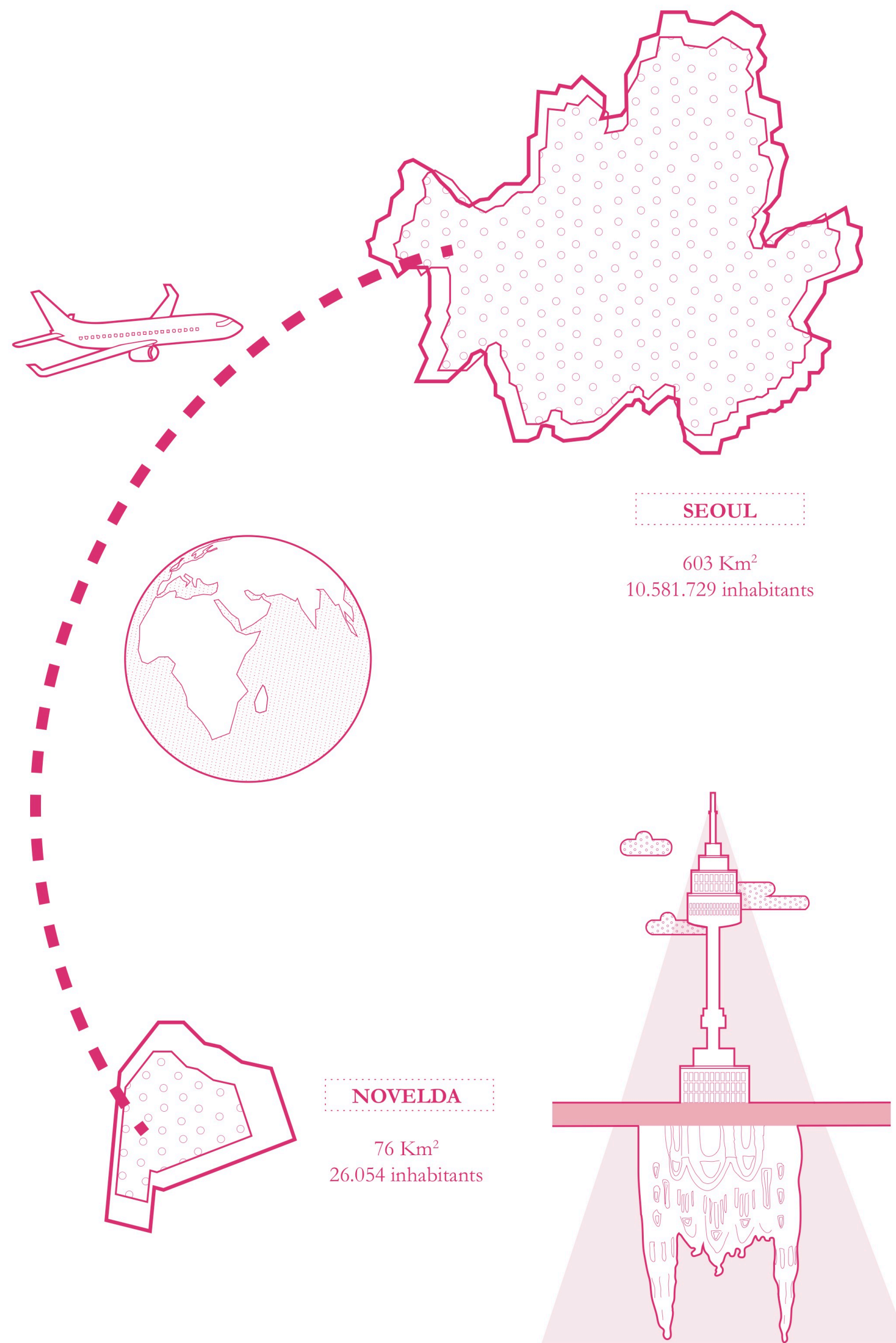

Figure 4. Scale change. 


\section{/ / Trigger/ /}

This journey begins with a study exchange trip to Seoul, capital of South Korea. Later, after this exchange, I decided to extend my adventure for another 4 months. Thus, 9 months were enough to get myself used to spicy food, to eating with chopsticks and speaking enough Korean to survive in a city like this. But above all, these months were enough to enter and intoxicate myself with a Korean culture that did not stop surprising me one single day.

The experience and, therefore, the life lessons I got from this country are situated at the starting point of this work, from an empirical position and an unprofessional look.

The experience of what I lived there cannot be a guarantee for knowledge, but I do consider that the experience, understood as the establishment of connections between agents, easily classifiable or not within one discipline or another, can be treated as the real guarantee. Thus, I have allowed for a perspective that is more closely related to our time, looking at what we want to see, what we do not, and to that which, even though we look, we cannot see it.

It should be said that much of what has been written here is the result of opportunity and a certain ability to listen and "capture" during these 9 months. Thanks to lectures and readings, colleagues and teachers, with whom I have a considerable debt, and those who have been forced to dialogue, since it has become necessary.

Farther away, I have tried to find that critical eye that will help me crumble this perspective, linking it and supporting myself on scientific knowledge. All this with the aim of understanding the city as the multiple results of the performance of a heterogeneous set of entities, which end up intertwining in relational networks. 


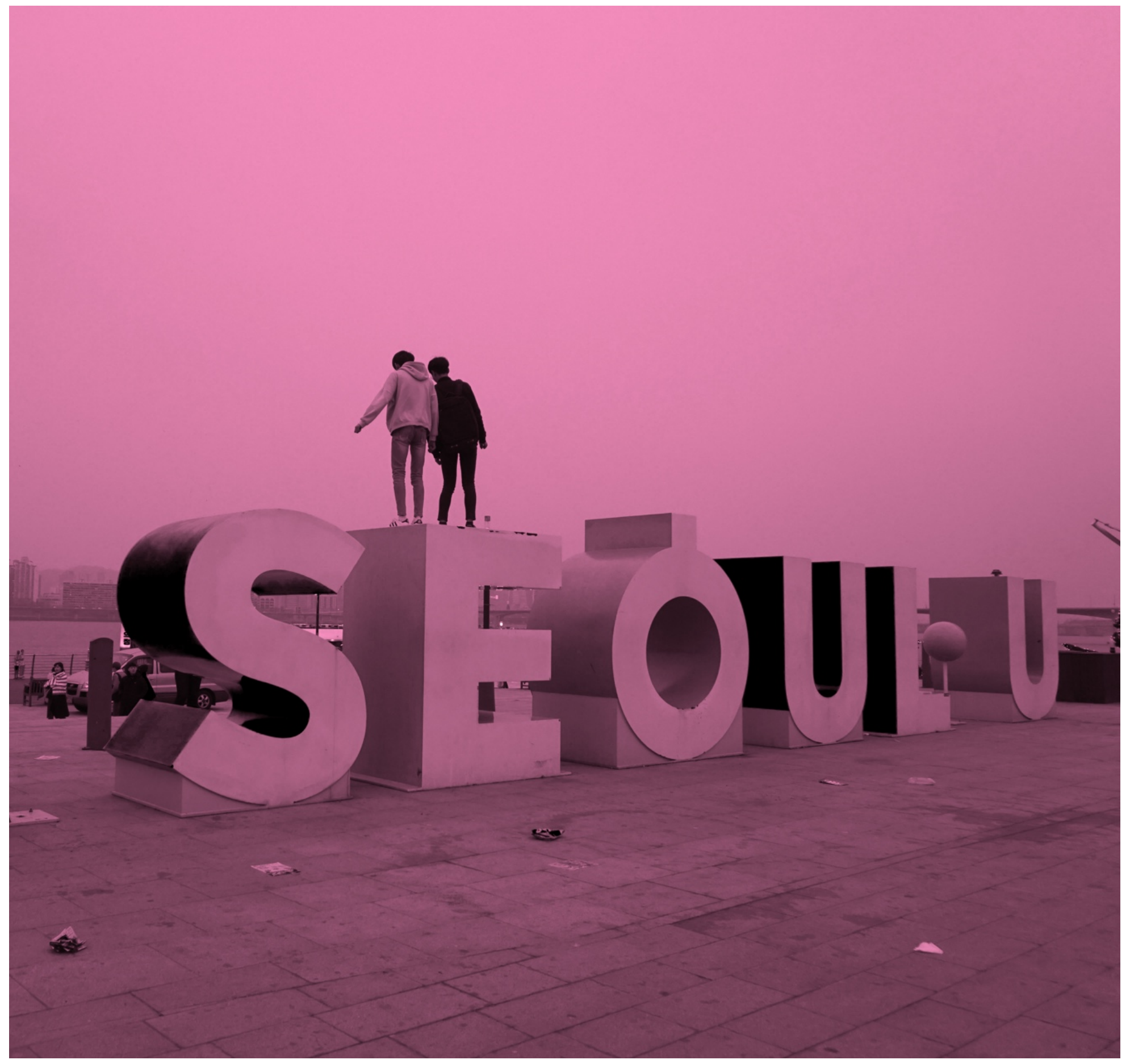

Figure 5: 28th March, 2017. Yeoido Park. 


\section{The CITY: Seoul}

\section{// Objectives //}

Seoul is one of the most densely connected metropolises, due to the large concentration of Korean population in the capital, which resulted from the period of great economic development. At that time, job opportunities and the quality of education were superior there than in the rest of the country.

The capital is also one of the fastest cities to be transformed in the world and is often portrayed by its global-media with a high technological and techno-oriental fetishism, or alternatively, as a guinea pig laboratory, where the latest technology is tested.

This has to do with South Korea being the cradle and home of famous brands such as Samsung and LG, and Seoul is the capital of the largest existing broadband.

But all these technologies and innovations coexist with the presence of some of the oldest traditions of Korean culture, which results in the convergence of a unique and contemporary techno-social environment. ${ }^{1}$

And, what effects can this techno-social environment like this have on the real lives of population in Seoul? How complex can this environment become related with the many networks that make up a city? What consequences may occur? What kind of architectures and other technologies will proliferate in an environment like this? What preliminary considerations are important for the development of new technologies in the context of South Korea?

\footnotetext{
${ }^{1}$ Jaz Hee-jeong Choi, «The city of connections: urban social networking in Seoul», ARC Centre of Excellence for Creative Industries and Innovation; Creative Industries Faculty MindTrek: 12th international conference on Entertainment and media in the ubiquitous era (6 de octubre de 2008): 189-93, doi:http://doi.acm.org/10.1145/1457199.1457241.
} 


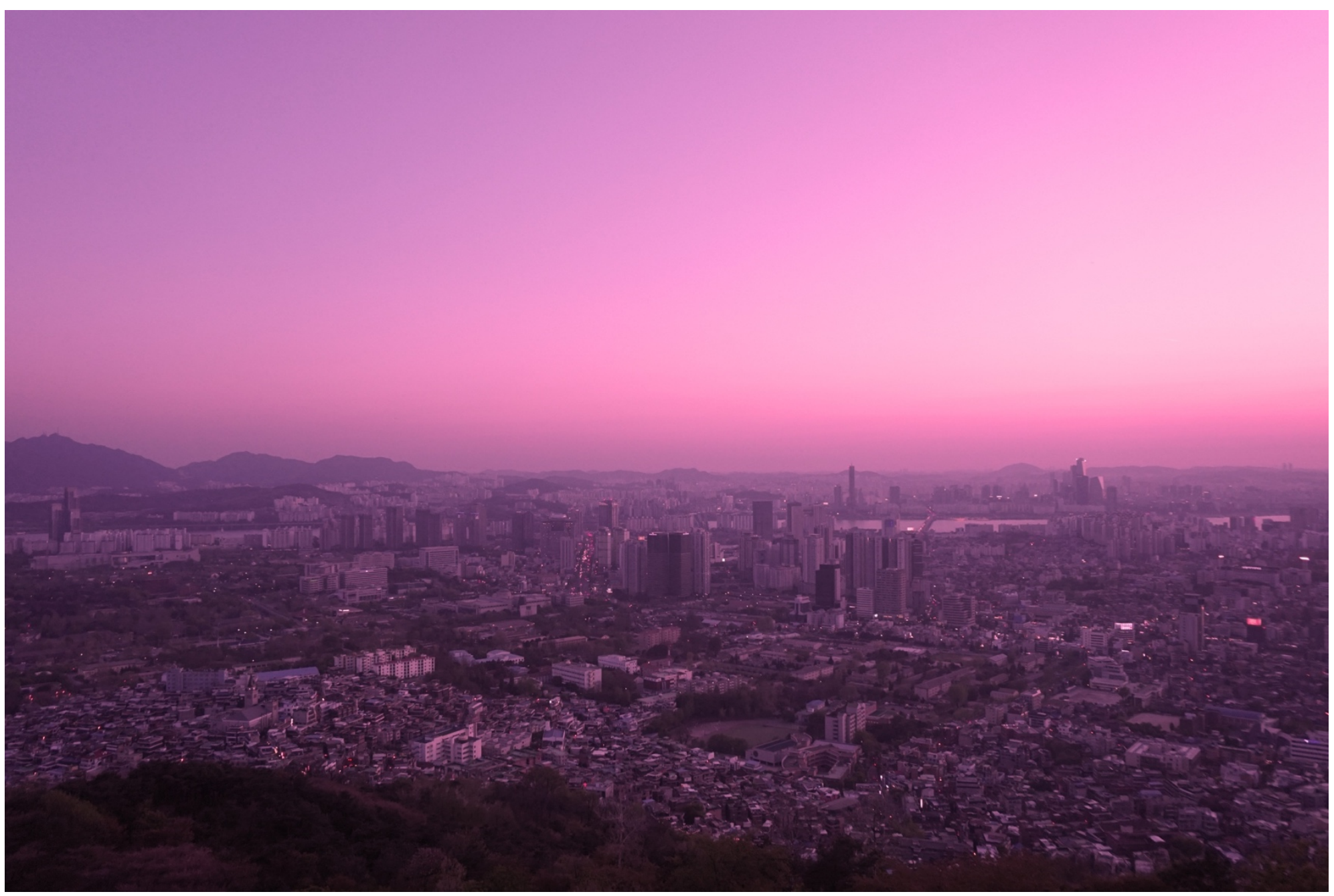

Figure 6: 26th Octoner, 2016. Views from the Seoul Tower. 


\section{// Descriptions//}

\section{- Economic Context -}

Seoul is home to about half of the population of the entire country, creating a very important economic engine. However, Seoul has not always been a place of economic and technological wealth. The damage caused since the Japanese invasion (1910-45) until after the Korean War (1950-53) left the country at the end of the global economic and political scale. Korea was at the same level and compared at the same time with poor countries in South-Africa. ${ }^{2}$

Over time, Korea has managed to position itself as the $11^{\text {th }}$ largest economy in the world, thanks to its rapid development, which gave way to major political, social and infrastructure reforms, but in turn, this rapid growth of the city and industrialization left consequences, which have greatly influenced Korean culture and behavior. ${ }^{3}$

\footnotetext{
2 Jaz Hee-jeong Choi y Adam Greenfield, «To connect and flow in Seoul: Ubiquitous technologies, urban infrastructure and everyday life in the contemporary Korean city», ed. Marcus Foth, Handbook of research on urban informatics: the practice and promise of the real-time city, 2009, 21-36.

${ }^{3}$ Choi, «The city of connections: urban social networking in Seoul».
} 


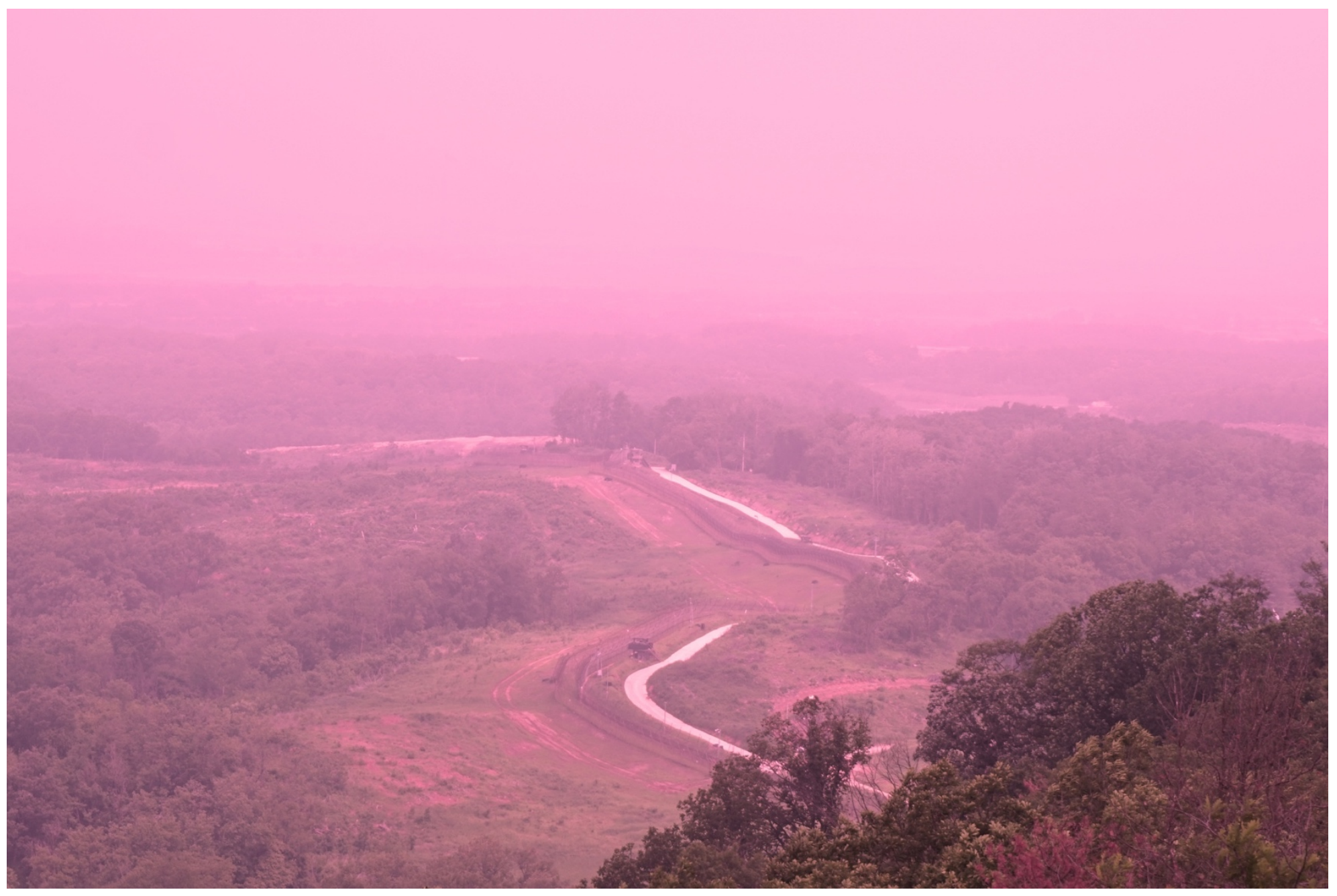

Figure 7: 8th June, 2017. Edge of the demilitarized zone with North Korea. 


\section{- Political and Social Context -}

In April 2013, the taunting and consequent aggressive threats by North Korea brought the Korean peninsula to the brink of confrontation, and subsequent negotiation. This threat has gradually become more serious, especially when the Committee of Peace in Pacific Asia announced, with most urgency, that the situation in the peninsula was approaching a thermonuclear war, given the eternal and obvious hostile actions between both arch enemies.

In spite of all this political severity and military confrontation, the capital and at the same time economic, political and cultural Korean center was in a process of development and deployment, totally opposite to the political situation which was taking place. ${ }^{4}$

PSY and his famous song 'Gangnam Style' was able to show and exhibit all his hedonism and lustfulness through his lyrics, despite the tensions and unconsciousness of the city's proximity to the border with North Korea, only 50 kilometers away.

\footnotetext{
4 Jung In Kim, «The birth of urban modernity in Gangnam, Seoul», arq: Architectural Research Quarterly 19, n. 4 (diciembre de 2015): 369-79, doi:10.1017/S1359135515000615.
} 


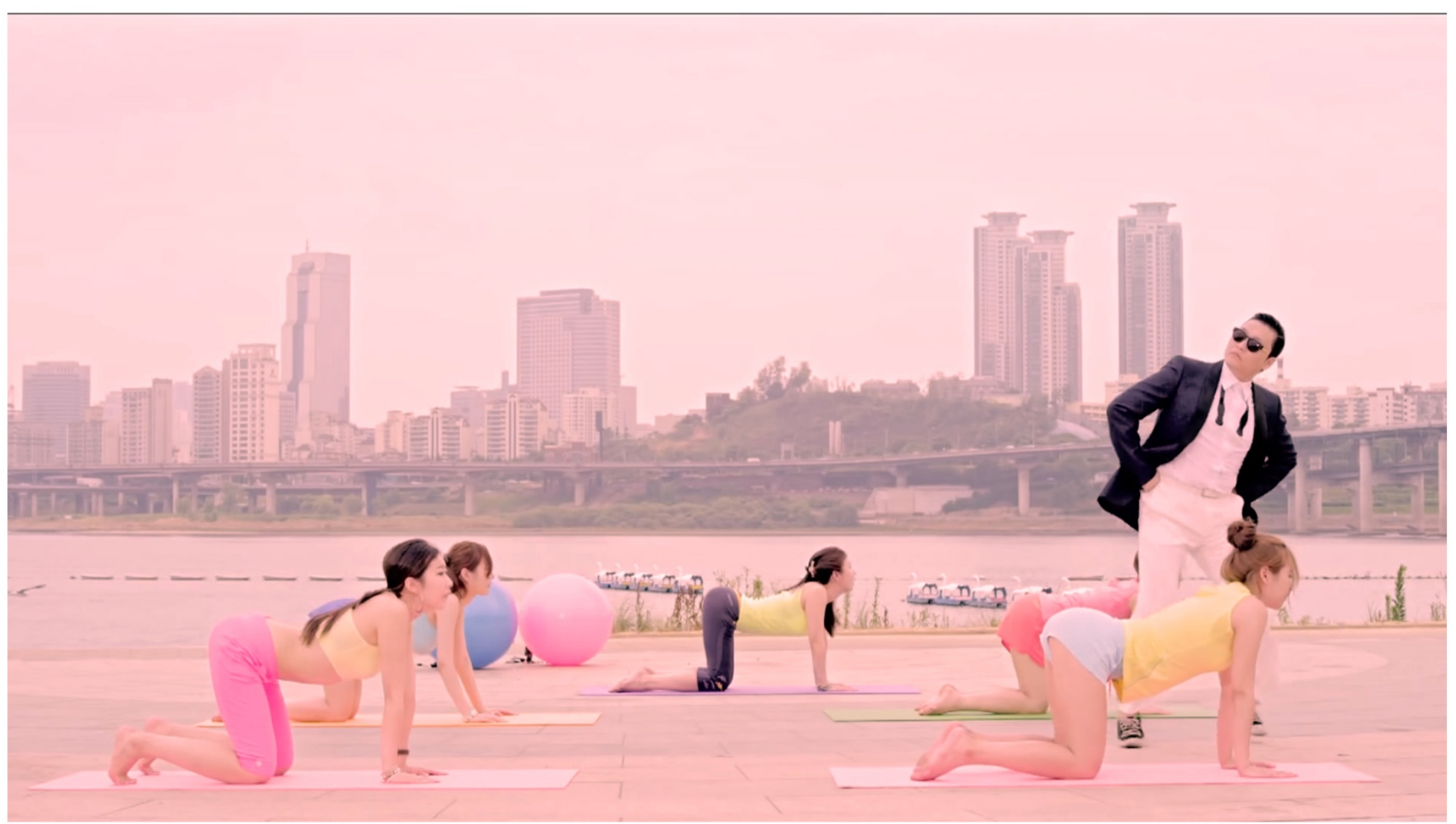

PSY - GANGNAM STYLE(강남스타일) M/V

2.946.314.400 visualizaciones COMPARTIR $\equiv_{+} \quad$-..

\section{officialpsy $\varnothing$}

Publicado el 15 jul. 2012

PSY - DADDY(feat. CL of 2NE1) M/V @ https://youtu.be/FrG4TEcSuRg PSY - 나팔바지(NAPAL BAJI) M/V @ https://youtu.be/tF27TNC_4pc 
The song had an important worldwide fame, was the most watched video in 2012 and until July 2017, the most watched in the history of YouTube. The song paid homage to how the colors and brightness of the city and its tall buildings overshadow the current political situation, trying to correct the existing pessimistic political environment.

This tribute, or rather critique, describes and makes a reading, in a satirical way, of the urban youth that walks the streets of Gangnam, a south-eastern district of the city which hosts around 1.7 million people. It is known for its crazy nightlight, being home for luxiry and appearances. ${ }^{5}$

Gangman is the symbol of this progress for South Korean culture, symbol of the incredible growth that has taken place from the most extreme agrarian poverty after a way, to being an economic power.

This certain security in economic aspects has given way, since the mid-nineties, to a Korean life that is based on bank loans, educating the country towards hard work and competitiveness in order to strengthen the national economy as a key for independence. 6 At times, that competitiveness has suggested the materialism that PSY hits with his song since 2012, suggesting that wealth is not as fabulous as it might seem, and pointing to the ridiculousness of utilitarianism and social classes 50 kilometers away from a country like North Korea. ${ }^{7}$

The song was a social satire that would be felt as smooth and friendly in the United States, but which sounded differently in South Korea. The subversive message broke records on Korean k-pop lists, which until now had been dominated by sweet cotton.

\footnotetext{
5 Ibid.

${ }^{6}$ Hyun Jeong Min, «New Women and Modern Girls: consuming foreign goods in colonial Seoul», Journal of Historical Research in Marketing 5, n. 4 (4 de noviembre de 2013): 494-520, doi:10.1108/JHRM-01-20130004 .

7 «Gangnam Style, Dissected: The Subversive Message Within South Korea’s Music Video Sensation - The Atlantic», accedido 3 de septiembre de 2017, https://www.theatlantic.com/international/archive/2012/08/gangnam-style-dissected-the-subversivemessage-within-south-koreas-music-video-sensation/261462/.
} 


\section{- Genre and Power -}

During the 20s and 30s, in the colonial city of Seoul, a group of women called "The New Women and the Modern Girls" expressed their modern identity, trying to differentiate themselves through their different dressing codes, their type of hair and makeup; visiting coffee shops, watching western movies, and consuming imported products. ${ }^{8}$

These women were admired by many others, and were considered pioneers of modernity, but they were also criticized under the pretext of allowing themselves a certain vanity, without considering the economy of their families and their colonized nation. ${ }^{9}$

Today, in the 21st century, these criticisms of modern women continue. In his song "Gangnam Style", PSY mentions the "Doenjang girl" or "Doenjang woman", translated as "woman of soybean paste". Popularly, they are the kind of women who prefer to eat a 2,000won ramen in order to buy a 6,000-won Starbucks coffee. This is due to the propensity to adjust their budget in basic expenses and be able to spend it on other products ${ }^{10}$ or consume luxuries paid by their parents or partners. ${ }^{11}$

This remarkable similarity between both eras is directly related to a behavior on the part of women who escape the limits of the traditional and idealized role imposed by the ideology of "Wise mother, good wife". An imposed ideology that represents the ideal of femininity and the status of women in the East Asian area, that is, China, Korea and Japan, adhering to neo-Confucianism and Korean nationalism, which are deeply rooted in the Korean society, and far from the Western appearance that meant lacking chastity; selfish and foolish. ${ }^{12}$

\footnotetext{
${ }^{8}$ Hyun Jeong Min, «New Women and Modern Girls».

9 Ibid.

10 «Gangnam Style, Dissected: The Subversive Message Within South Korea’s Music Video Sensation The Atlantic».

11 Hyun Jeong Min, «New Women and Modern Girls».

12 Ibid.
} 

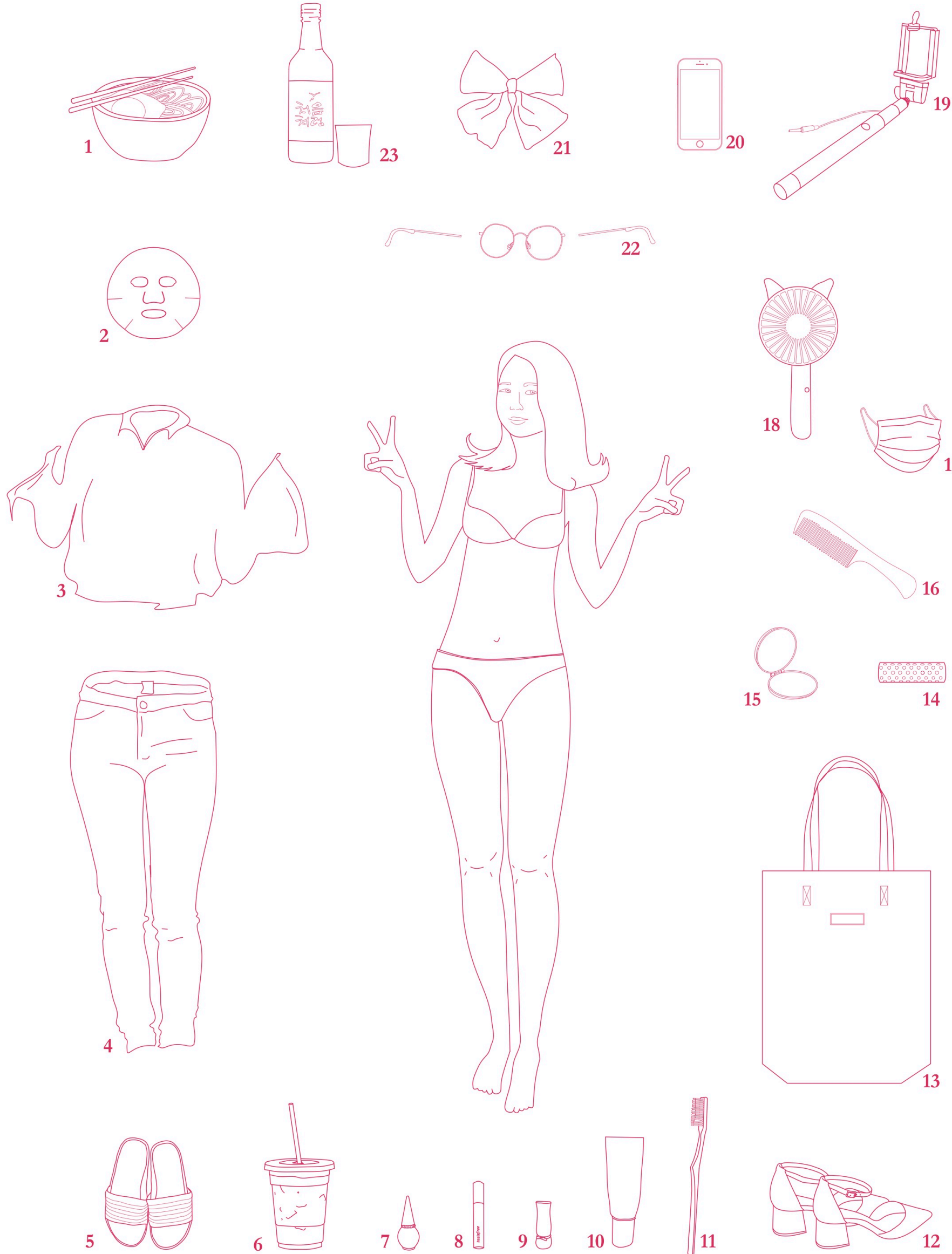


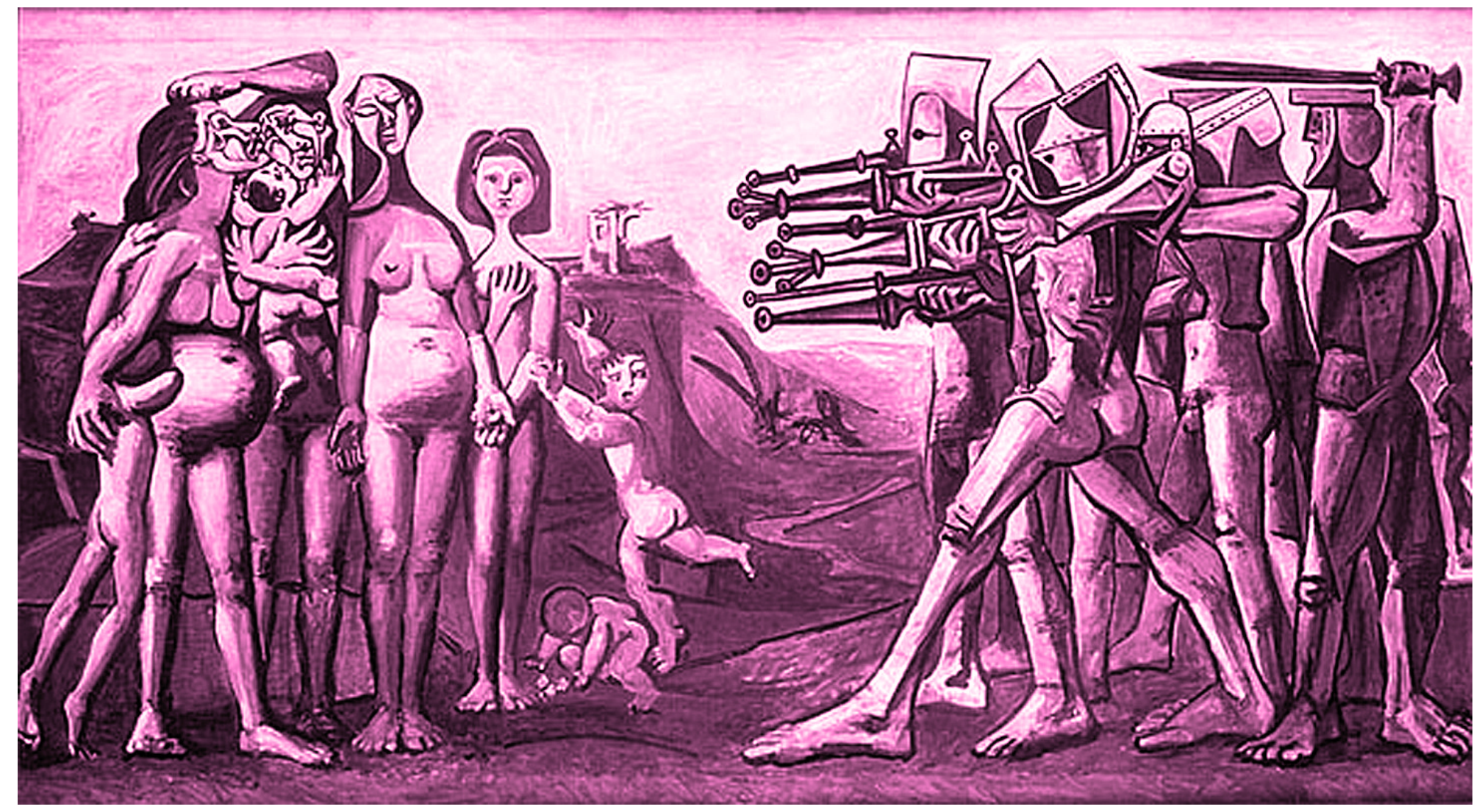

Figure 10: Massacre in Korea, Picasso, Pablo. 1951 
This conservative Confucianism and Korean nationalism emerged between 1910 and 1945, when the Korean peninsula was invaded and colonized by Japan, and it still survives in today's society. The colonization provoked great changes and repressions, both in culture and language. Many Koreans saw the need to change their names to others with Japanese influence. In addition, children were forced to learn Japanese in schools. ${ }^{13}$ During the occupation, not only they were victims of repression, but also of various punishments, executions, rapes, forced labor, looting, hunger, sexual slavery, and medical experimentation. ${ }^{14}$

The Japanese colonial laws stimulated the increase of a Korean nationalist sentiment. After such repression, a partial press freedom was allowed, but the attempts for a declaration of independence stoked and strengthened the feeling of national identity and patriotism of Korean people.

Later, the Second World War did not improve the repression: the Japanese government created the groups of "comfort women" as a strategy of war, made up of young women from Korea, China, Japan and the Philippines who were forced to become prostitutes, whose job it was to entertain the colonial soldiers, either through games or sexual practices.

Between 80,000-280,000 Korean youths from the poorer classes were recruited and abducted by the Japanese government, who had promised to offer them a job in the factories, or simply mobilized and forced to serve Japanese soldiers in military brothels. These women were called "comfort women", who maintained a distinction with the so-called Japanese "comfort women", which also existed. But with the difference was that they were voluntary participants, who followed commercial ends and were treated differently. Korean women, on the other hand, were treated with much more cruelty.

The "comfort women" were forced to have sex with Japanese soldiers from 10 to 30 times a day, and were subjected to torture, bites, burns, and even stabbing. Many women were infected with the numerous contagious diseases in military brothels, and many others were victims of suicide. 15

\footnotetext{
13 Pyong Gap Min, «Korean “Comfort Women”: The Intersection of Colonial Power, Gender, and Class», Gender and Society 17, n. ${ }^{\circ} 6$ (2003): 938-57, doi:10.2307/3594678.

14 Aniko Varga, «National Bodies: The "Comfort Women” Discourse and its Controversies in South Korea», Studies in Ethnicity and Nationalism 9 (s. f.): 287-303.

${ }^{15}$ Min, «Korean "Comfort Women”».
} 


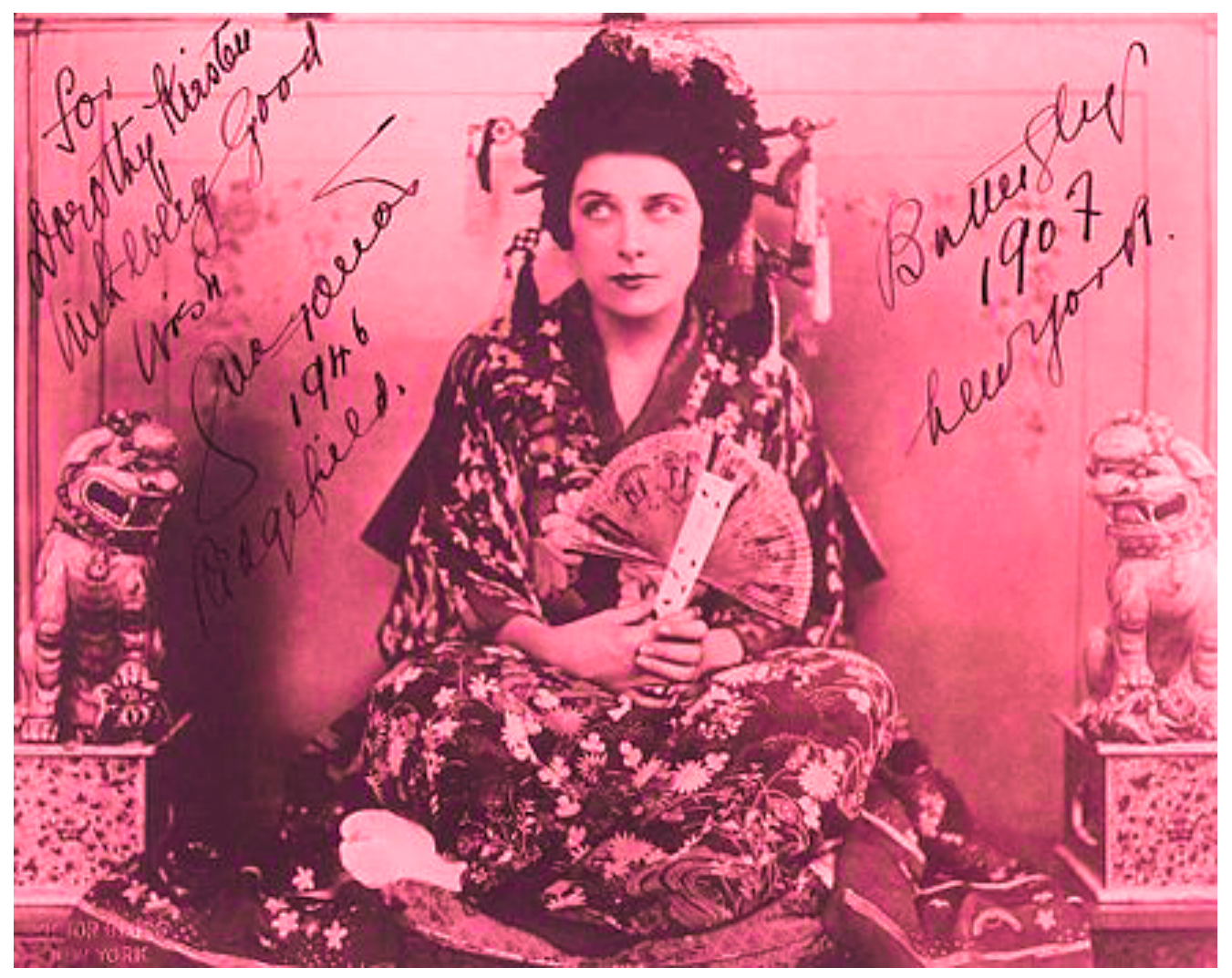

Figure 11: Geraldine Farrar as Madame Butterfly, 1907 
During Japan's defeat during World War II, Japanese soldiers abandoned these women after five years, and in some cases even killed them. Many of them returned to Korea, but due to popular shame, they were not allowed to return home and live with their parents. Both physically and mentally sick, many of them failed to live a normal life, and those who did, were divorced by their secret past or their infertility, due to illnesses and psychological traumas of fear of man. ${ }^{16}$

After the extinction of the "consolation woman", given by the end of the Japanese invasion with its surrender in 1945 at the end of the Second World War, Korean nationalism did not stop growing with the hope of recovering its identity, its culture, and its language.

The intrusion of Western commercial and military power in the late nineteenth century forced Korea into a global capitalist economy, and the traditionalist response to this crisis of values was to orthodoxly protect neo-Confucianism and reject all heterodox foreign values, although after signing treaty with Japan it became increasingly difficult to maintain orthodoxy and isolate the country of Korea from Western values. ${ }^{17}$

Upon returning from war to their home countries, the Western military propagated a version of Asian women with values of hyper-sexuality and submission. The result of this version was the first contact established by Westerners with Asian women, and its spread together with the success of the famous work Madame Butterfly, played in the opera up to this day, and based in part on the novel by Loti, it generated a multiplying effect. ${ }^{18}$

\footnotetext{
16 Ibid.

${ }^{17}$ E. J. Choi, «The Body in Packaging Culture: Researching Cosmetic Surgery within Korea’s NeoConfucian Culture», Master thesis, (21 de septiembre de 2015), http://dspace.library.uu.nl/handle/1874/320457.

18 Min, «Korean "Comfort Women”».
} 


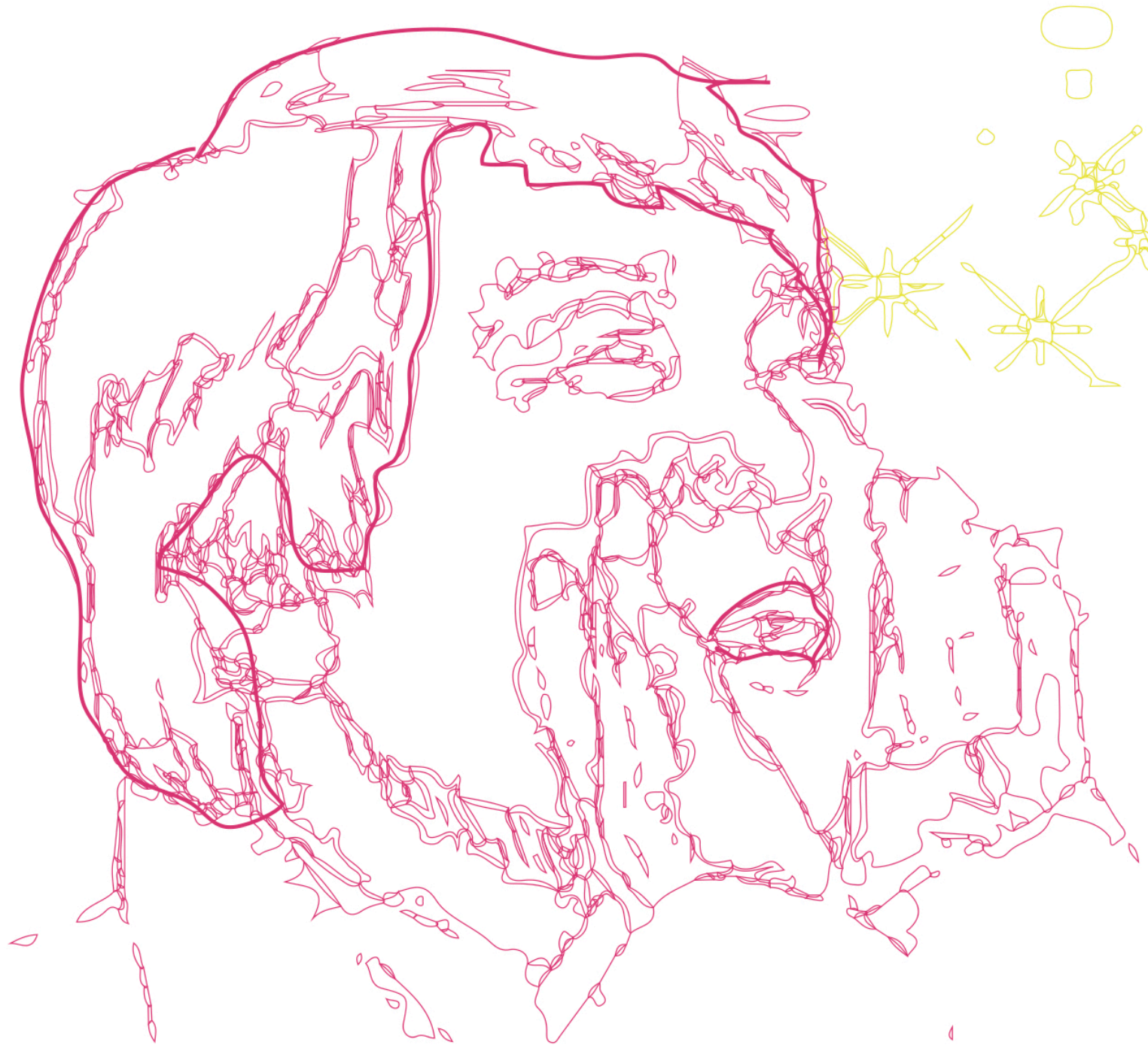

Figure 12: Recovery of an identity. 
The installation of the US military apparatus in South Korea, between 1945 and 1949, after the Second World War, as in other colonies, never allowed South Korea to have the opportunity to decolonize, that is, there has always been a neo-colonial domination about the country, which has led to perpetuate even more the anti-colonial Korean nationalism. ${ }^{19}$

The installation of the troops of the Soviet Union and the United States took an agreement for the division of the peninsula in 1948; a division that was severely affected and accentuated with the elections held in order to establish a government. These elections came up to fracture the peninsula with the establishment of a Communist Government by the North, and its intrusion invading the southern part of the border established by the US and Soviet troops. This invasion ended up unleashing the Cold War in 1950, ending in 1953 with an armistice and establishing the border and the Demilitarized Zone.

As far as we can see, since 1945, the Korean society has been overwhelmed by new and old ideologies, social classes and political groups. So, this anti-colonial nationalism has tried to keep the Confucian ideology present within the society. Thus, it has tried to claim masculinity, promoting a discourse that homogenizes the nation and normalizes women and their chastity, in order to show their belonging to the patriarchal order. ${ }^{20}$

\footnotetext{
19 Elaine H. Kim y Chungmoo Choi, eds., Dangerous Women: Gender and Korean Nationalism, 1 edition (New York: Routledge, 1997).

${ }^{20}$ Ibid.
} 

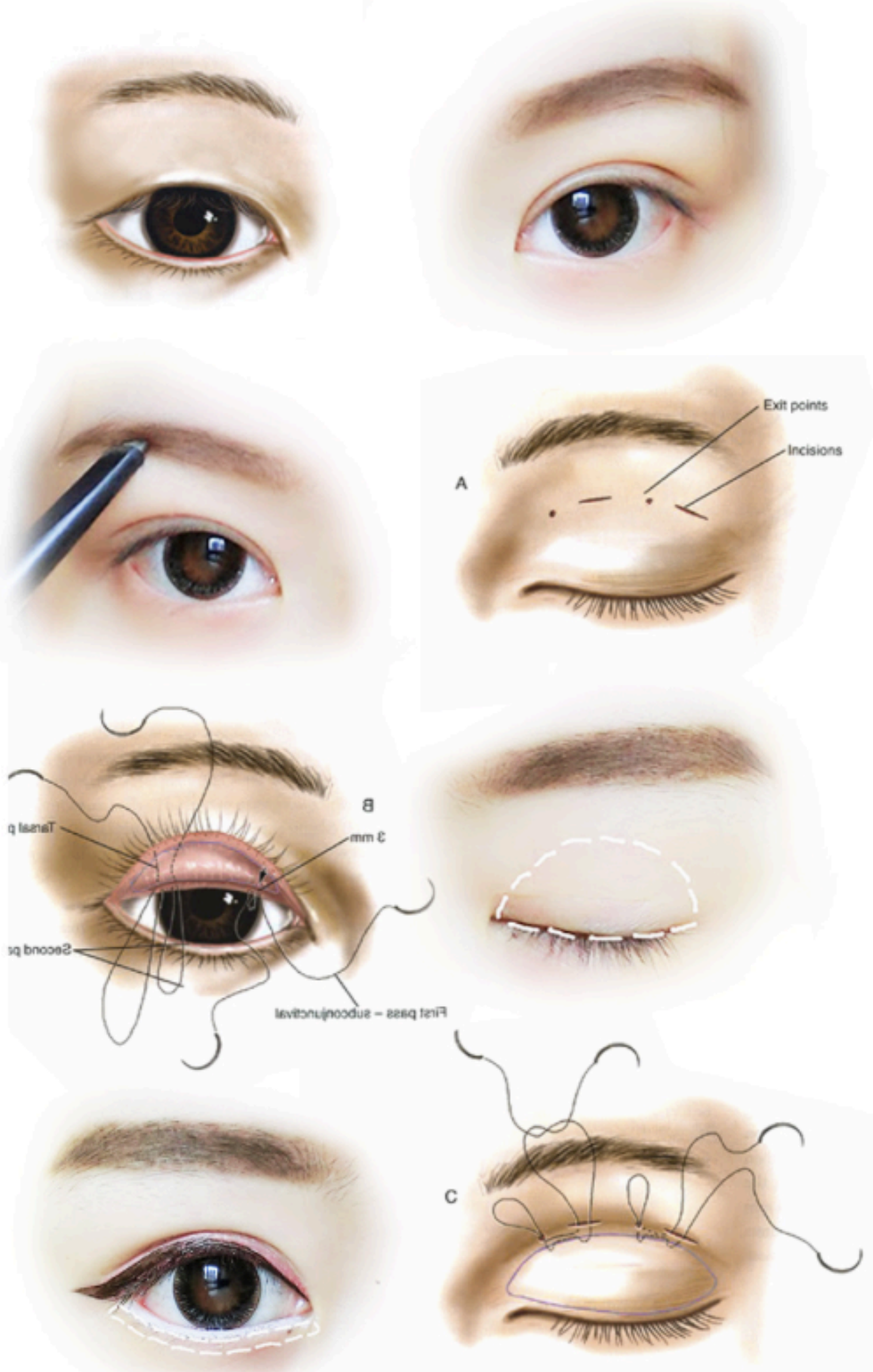

Figure 13: Going Fluid Project for the Instanbul Biennial, carried out by Common Accounts.. 
During Korean history, there have been many restrictions imposed on women by Confucianism and the male nationalist discourse, prostitution, the active role of women in the anti-colonial struggle, and the representation of Asian women in the literature and cinema of the twentieth century.

However, stereotypes about Asian women do not end here. After a post-war period with North Korea, and much earlier with Japan, it resulted in a precarious situation for the Korean society. Hunger, lack of education and other basic needs kept on hitting the Korean people.

Korean society in the post-war situation, added to the bad economy and an education that was different from the Western caused in them a situation of insecurity in front of the US military, doctors and missionaries, whose women also preferred the others. Well, many parents put pressure on their daughters to find a partner in American soldiers, in order to raise their social status and thus improve their lives and hope for a better future. Therefore, parents of Korean women collaborated in the interest of the women about the vanity and materialism that we still see today in the Doenjang girl.

Upon arriving in the United States, many Korean women faced discriminatory laws and a state ban on interracial marriage between Americans and Asians, threatening that those who broke the law could lose their US citizenship.

This discrimination arose after 1850, when, attracted mainly by the gold rush, communities of Chinese people began to arrive in the United States to work. The Americans, uncomfortable because of the cultural difference, and overwhelmed by the number of immigrants arriving in masses, created this type of discriminatory laws that prohibited the obtaining of properties and exclusion from factory jobs, since they considered them "less manly" and forced them to hold jobs that were carried out by women at the time.

Given this discrimination, many of the doctors and missionaries who were in Korea after the war began to devote themselves to the world of surgery, in order to make the Korean woman less Asian, and thus making them able to get married in the United States. 


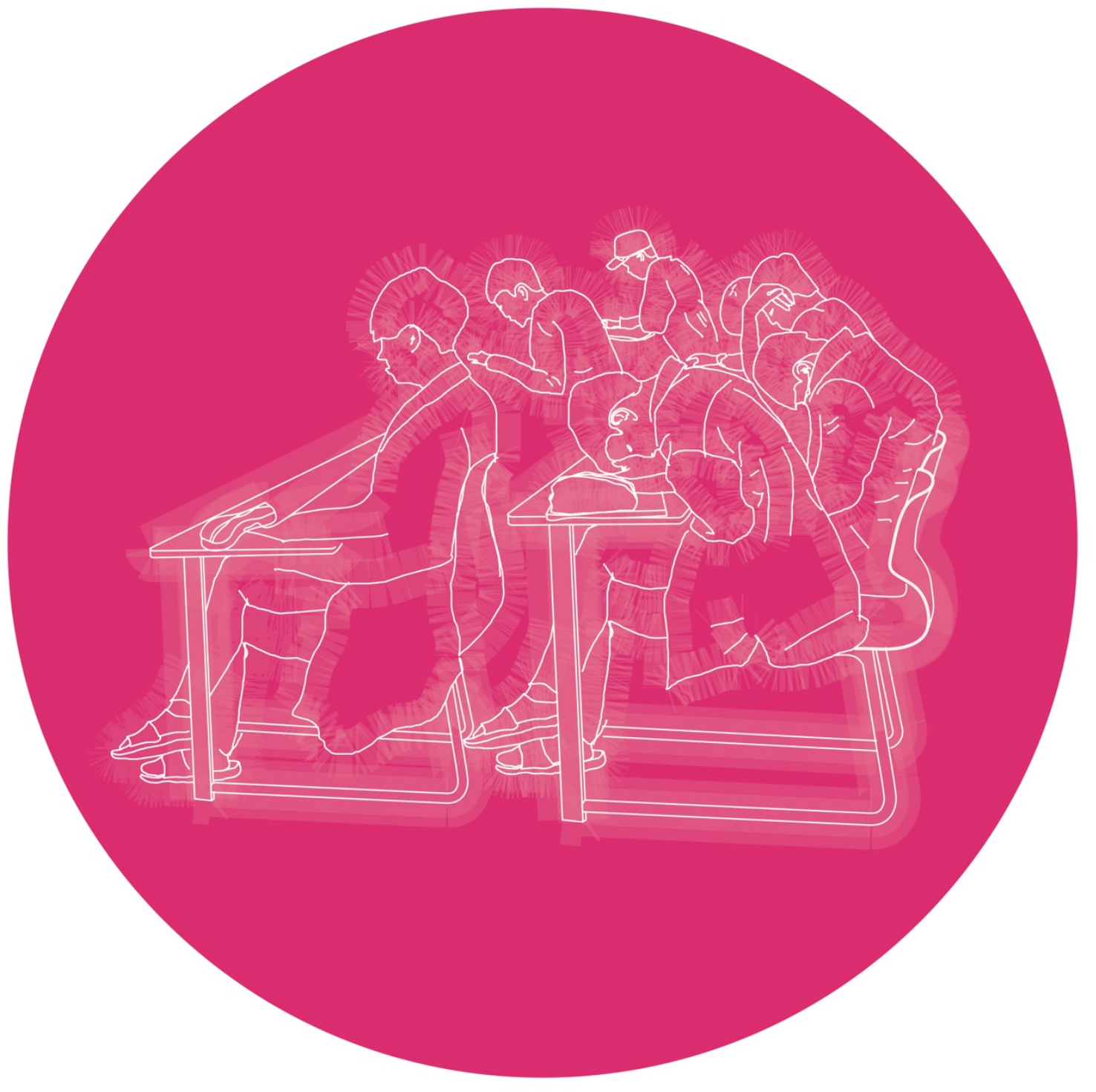

Figure 14: Korean students in a state of inemuri in class after their study nights. 
Currently, South Korea is the country with the highest rate of cosmetic surgeries, and in addition, Seoul is known as the capital of beauty (though not received at birth) of East Asia. According to the International Society of Aesthetic Plastic Surgery, one out of five women has received at least one surgery. ${ }^{21}$

This comes to reflect the intense materialism created through this discrimination and denigration of the figure of the woman, suffered for years in Korean society, the immense competitiveness of the public conscience and the high pressure to which society is subjected so as to find a partner; a pressure that is extended to education and the professional field.

As a sign of this pressure, the contemporary custom has emerged to give away the first operation of plastic surgery for the merit of having reached the university by parents' daughters. This merit of their long hours of study is gratified given the high demand that is given to the studies from dusk till dawn.

South Korea has the second best education system in the world, but in exchange for a high price, because the country has the top suicide rates due to school stress, or rather problems related to their parents, being suicide as the first cause of death between 15 and 24 years. This is a great concern for the state, which tries to fight against it through laws prohibiting private academies from giving classes at night. And, even then, they are still short hours to get a place in the best university of the capital and the country.

${ }^{21}$ Choi, «The Body in Packaging Culture». 
1. Both dorms and student residences and apartments are distributed by sex, restricting the entry to the opposite sex. //

2. Dorms are usually chosen by the parents of first-year students, since they maintain a controlled and restricted entry and exit schedule from $5.30 \mathrm{am}$ to $00.00 \mathrm{am}$. If your entry takes place after those hours, it causes misconduct which results in an expulsion. //

3. The rooms are shared, so that students live under the supervision and protection of a roommate. //

4. Before marriage, the responsibility of the parents, under the customs of neo-Confucianism, dictates to protect and supervise the sexual life of their children. In case of living alone and not receiving protection, your reputation is at risk of being denigrated.22//

5. The windows in rooms, generally, are 40 by 40 centimeters, as in order to avoid any suicidal attitude. //

\footnotetext{
22 Jesook Song, «'A room of one's own': the meaning of spatial autonomy for unmarried women in neoliberal South Korea», Gender, Place \& Culture 17, n. ${ }^{\circ}$ (1 de abril de 2010): 131-49, doi:10.1080/09663691003600264.
} 


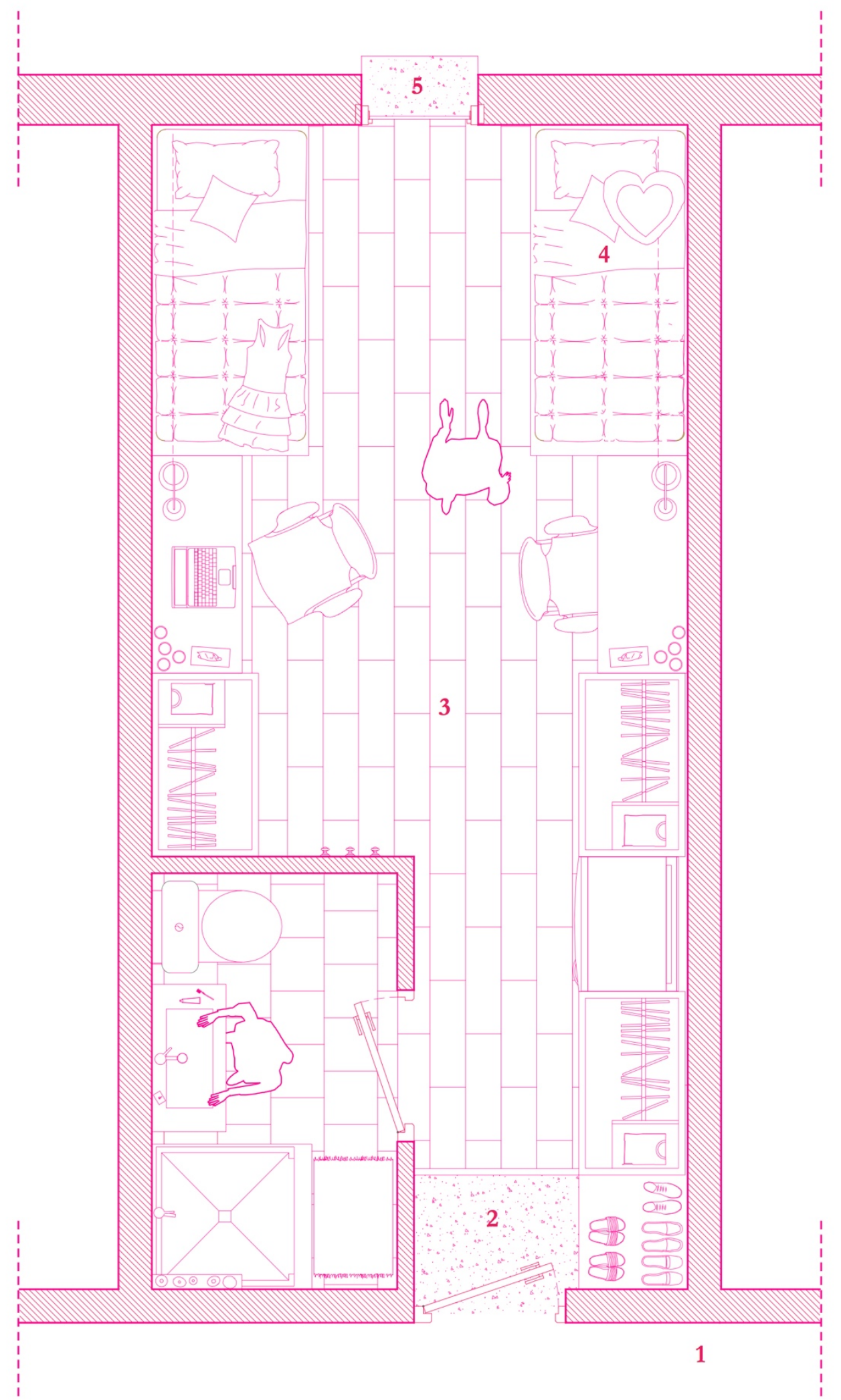

Figure 15: Floor of a student room. 1/100 scale. 


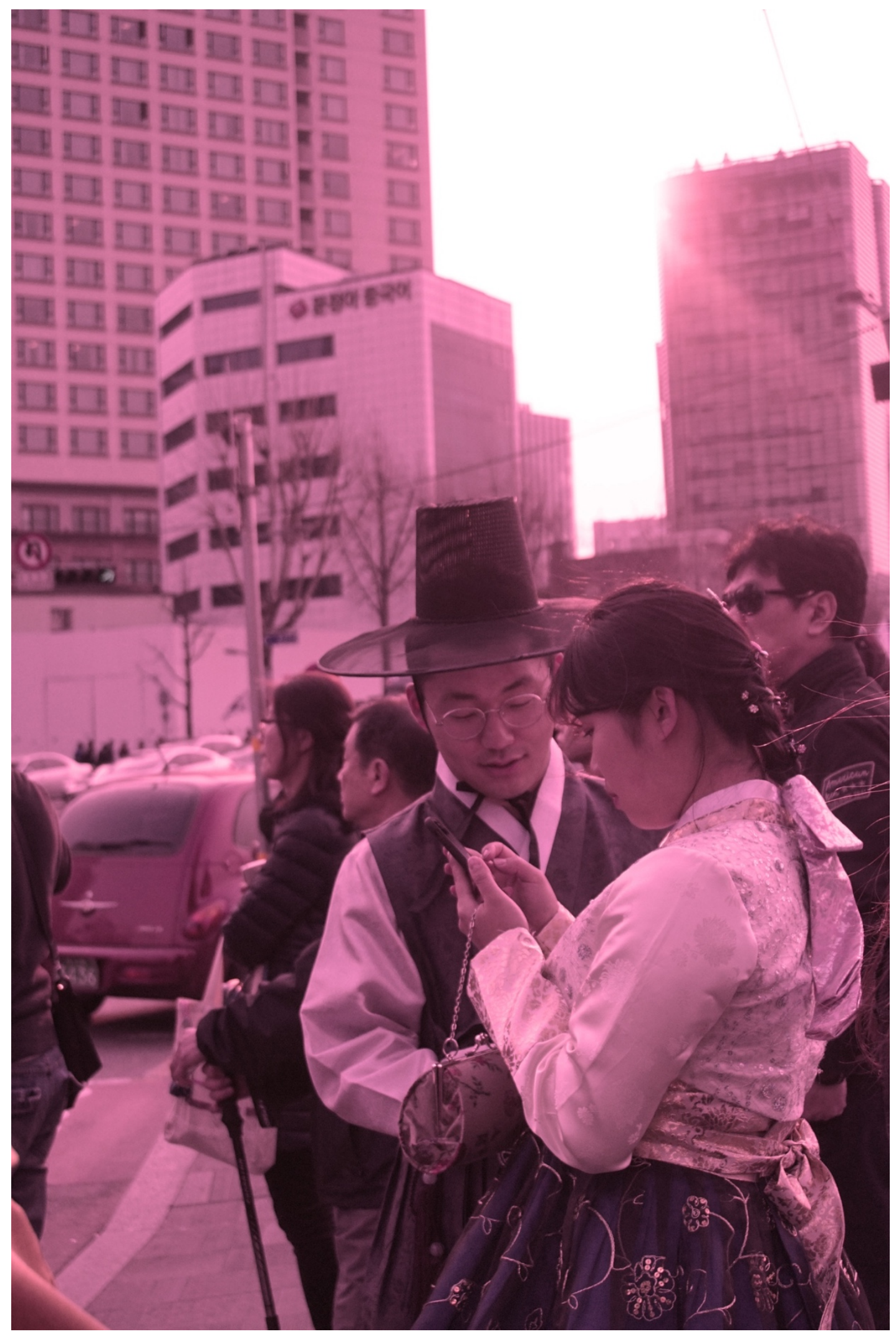

Figure 16: 26th March, 2017. Korean couple dressed in Hanbok, Insadong. 
The Korean woman, by social convention, lives in her parents' house before marriage; this is due to the customs and traditions of solid Neo-Confucianism in the country since the last Korean dynasty. Culture dictates to protect and supervise unmarried daughters, in order not to risk tarnishing their reputation.

The family has a duty to pressure their daughter to look good, keep her appearance, be well educated, etc., in order to have a good position in the market of finding a partner, which would motivate her to move out of the parental house. Marriage is still conventionally considered as the only option for most young Korean women who want to live away from their parents.

The age at which the majority of women unite in marriage in South Korea is currently over the 30 years. If women over age, parents suggest they move put, in order not to lose their reputation, not the women's, but their parents' in relation to their circle of friends, neighbors, workmates or even the church. Parents think that moving out can be the best option to stop meddlesome questions from family members about when they are getting married, or whether they already have a boyfriend or are still single. 


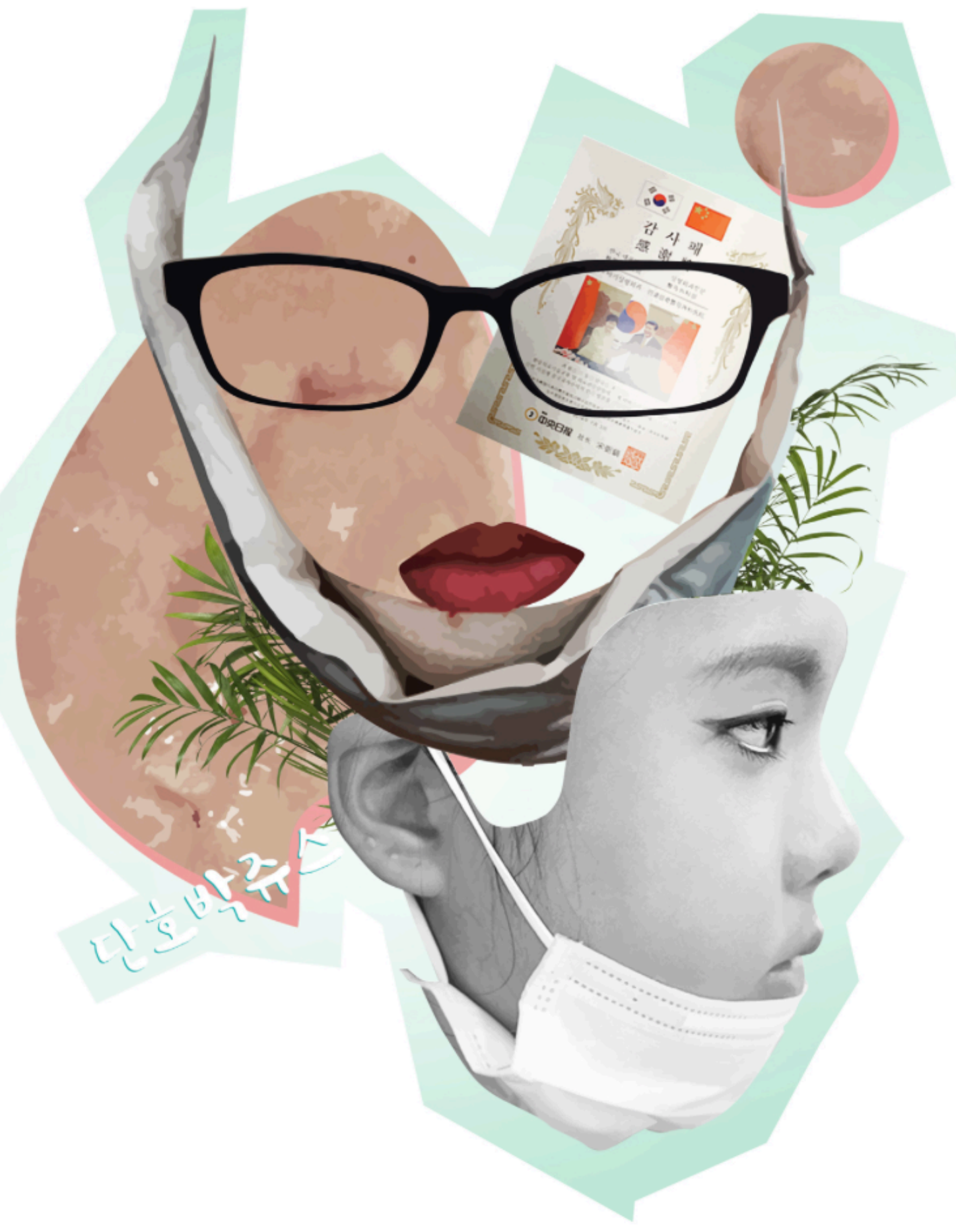

Figure 17: 'Going Fluid' Project for the biennial in Istanbul, created by Common Accounts.. 
The Confucian norm focused on family and marriage is not only manifested in the social or family pressure to marry and reproduce, but it is embedded even in the Korean bank loan regulations for housing. This is due to the control that the state has had upon the banks until 1997. 23

For example, a single person under 35 is not allowed to request a bank loan. For an access to housing, the person would have to do it from the most conventional way in South Korea: the "Jeonse".

The Jeonse consists of a lease that involves a deposit of approximately one third or a quarter of the sale value of the home, from the tenant to the owner. From there, the tenant is allowed to remain on the property "free of rent", that is, without having to make any additional monthly payment, until the lease contract ends, which is generally two years. After these years, the owner makes a refund, taking the rent money from the deposit. This deposit is protected during this time by a lien issued against the property for the amount given.

In contrast, now private banks consider that a married couple, or a couple with plans for a future marriage are eligible and allowed to receive loans, since they need an independent house. Also, it may be also considered that they are to receive a dowry after getting married, provided to them by their parents.

This is not only a discriminatory law; it is a repression of the Korean state linked to Confucianism and patriarchy, which supports marriage and reproduction. ${ }^{24}$

\footnotetext{
23 Ibid.

24 Ibid.
} 


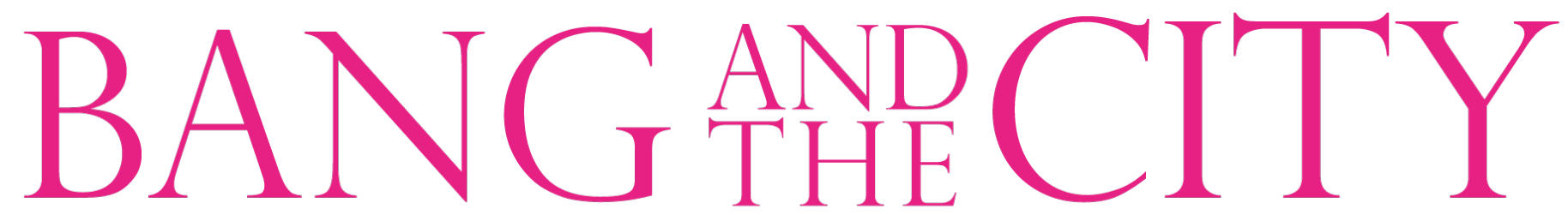

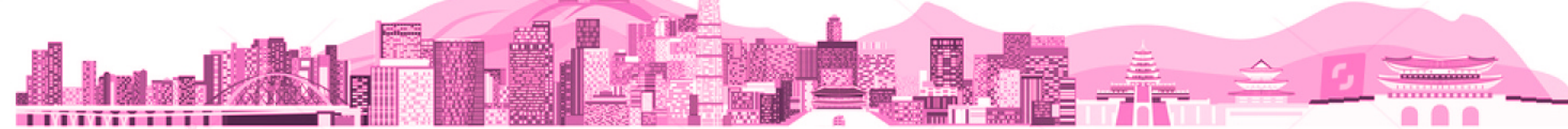


"Bang" is commonly translated as "room" in English. While in the Western country a room could be perceived as a single-purpose space, designed, designated and provided for a specific function, the traditional Korean culture supports the multiplicity of functions of a "bang", considered to be more flexible, and which may suffer a metamorphosis into another context or specific space, according to the will of its occupants. Therefore, we could say that the fundamental difference of its translation between the Korean way of creating a space and the Western one is often overlooked: it is all the social construction that space contains..$^{25}$

\footnotetext{
25 Jaz Hee-Jeong Choi y Adam Greenfield, «To Connect and Flow in Seoul: Ubiquitous Technologies, Urban Infrastructure and Everyday Life in the Contemporary Korean City», ed. Marcus Foth, Handbook of Research on Urban Informatics: The Practice and Promise of the Real-Time City, 2009, 21-36, doi:10.4018/978-160566-152-0.ch002.
} 


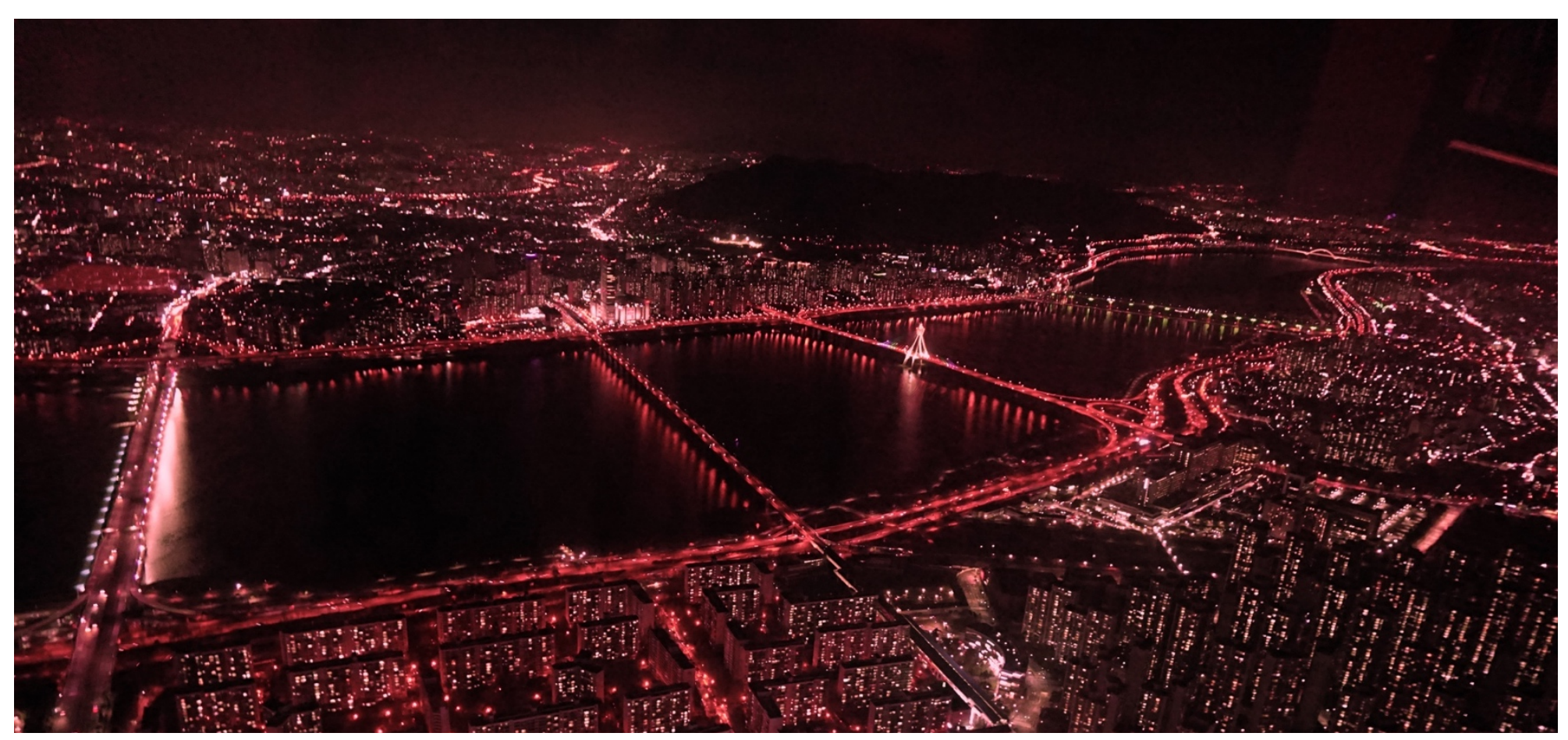

Figure 18: 26th April, 2017. Views from the Lotte Tower, the fifth highest tower in the world. 
The city of Seoul has kept adapting itself through different infrastructures and technologies after the Japanese invasion and the division war with North Korea, and also, with an important American military presence, which has helped in all its economic and social development

The Bang appears to be an authentic model of infrastructure in the construction of the Korean contemporary society, since it makes it possible to visualize the great number of connections that are established between the different agents, either human or not, that define their social context.

This model of space has not only managed to build its identity as a project, but it has also managed to blur the rigid classification between the micro and macro sides of its relationships and agents, providing its context with the necessary tools to travel in the interactive landscape, under which the contemporary city is presented to us.

According to Bruno Latour, the macro side no longer describes scenes or major agents in which the micro is immersed. On the other hand, in the contemporary city, the macro limits equally local or micro places, which are simply connected with many others through mediators. Therefore, we no longer talk about the size of the scale, or about whether one is larger than the other: we speak of connection, of one being more connected than another. The scale, for the contemporary city, is a matter of connectivity. ${ }^{26}$

\footnotetext{
${ }^{26}$ Pitarch, Pedro, «Building from controversies», Bartlebooth IV : Las Virtudes, septiembre de 2015.
} 
The city of Seoul, endowed and equipped with connectivity tools like any contemporary city, allows us to abandon the conception of scale of the modern tradition imposed in urbanism, and is constructed as a complex process, in which, the disparate and the controversy of their culture as construction values. ${ }^{27}$

Korean culture has found in the city of Seoul a new place of expression in which the heterogeneous and disparate are admitted, and conflicts welcome. Contemporary life has generated a territory of situations that constitute useful models from which to define tools with which to equip the ways of building society.

The bangs, as a tool, blurs the obsolete disciplinary as well as it limits and allows navigating in a relational ocean, from which the scale is defined. It is here where the micro and macro prove no longer useful to define situations of greater or lesser density within this network of connections.

By rereading the emergence of the Bang, we will extract models that can be used as tools for the construction of identities in the contemporary city. It is a model that is presented as a true urban project, in which the social function of human and non-human agents is constructed through the establishment of connections. The bang appears a model of mediation, whose reading and reassembly makes it a useful tool for the construction of the contemporary city.

\footnotetext{
${ }^{27}$ Pitarch, Pedro, «Building from controversies», Bartlebooth IV : Las Virtudes, septiembre de 2015.
} 


\section{BANG ANHECITY}

The city is connections between bangs.

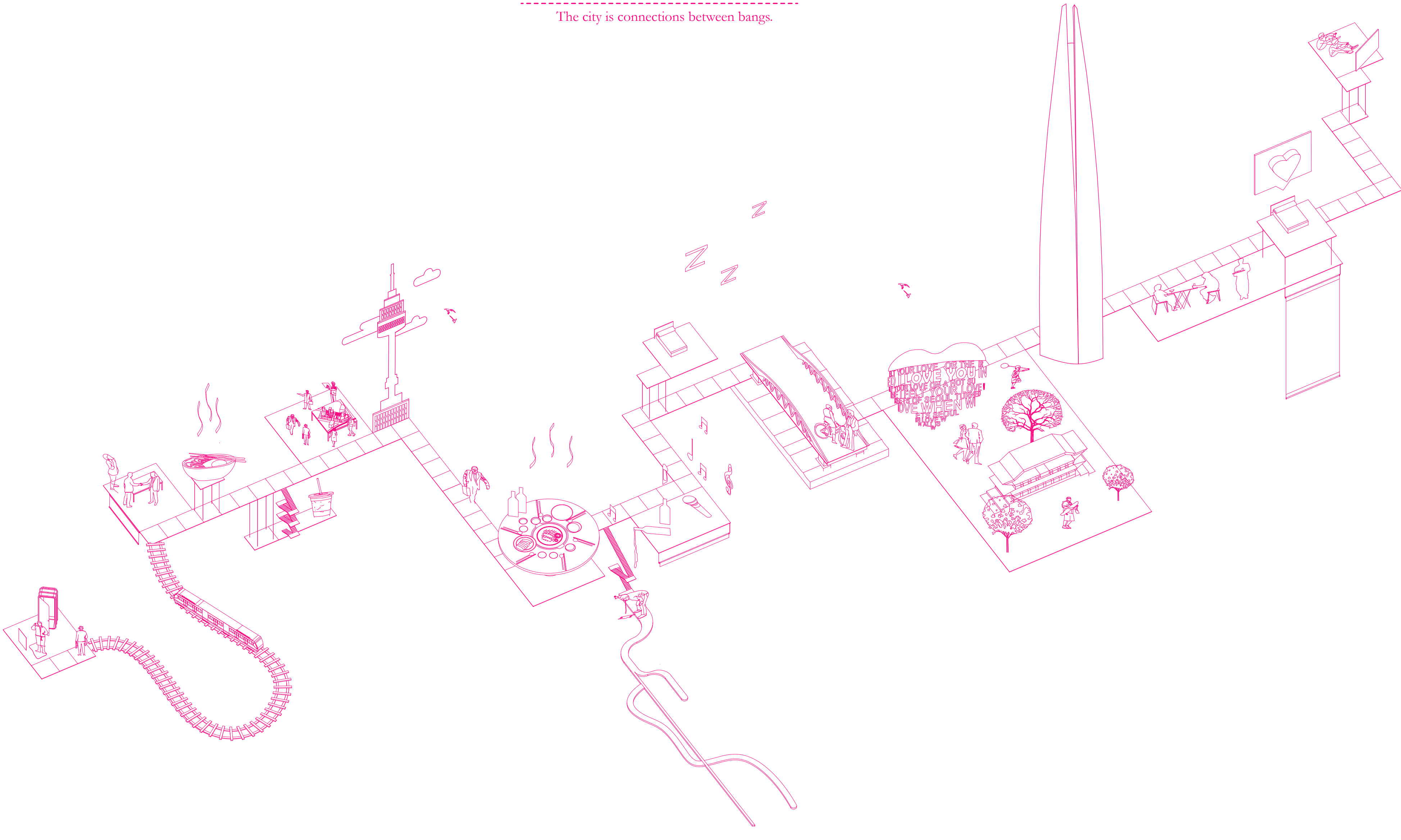




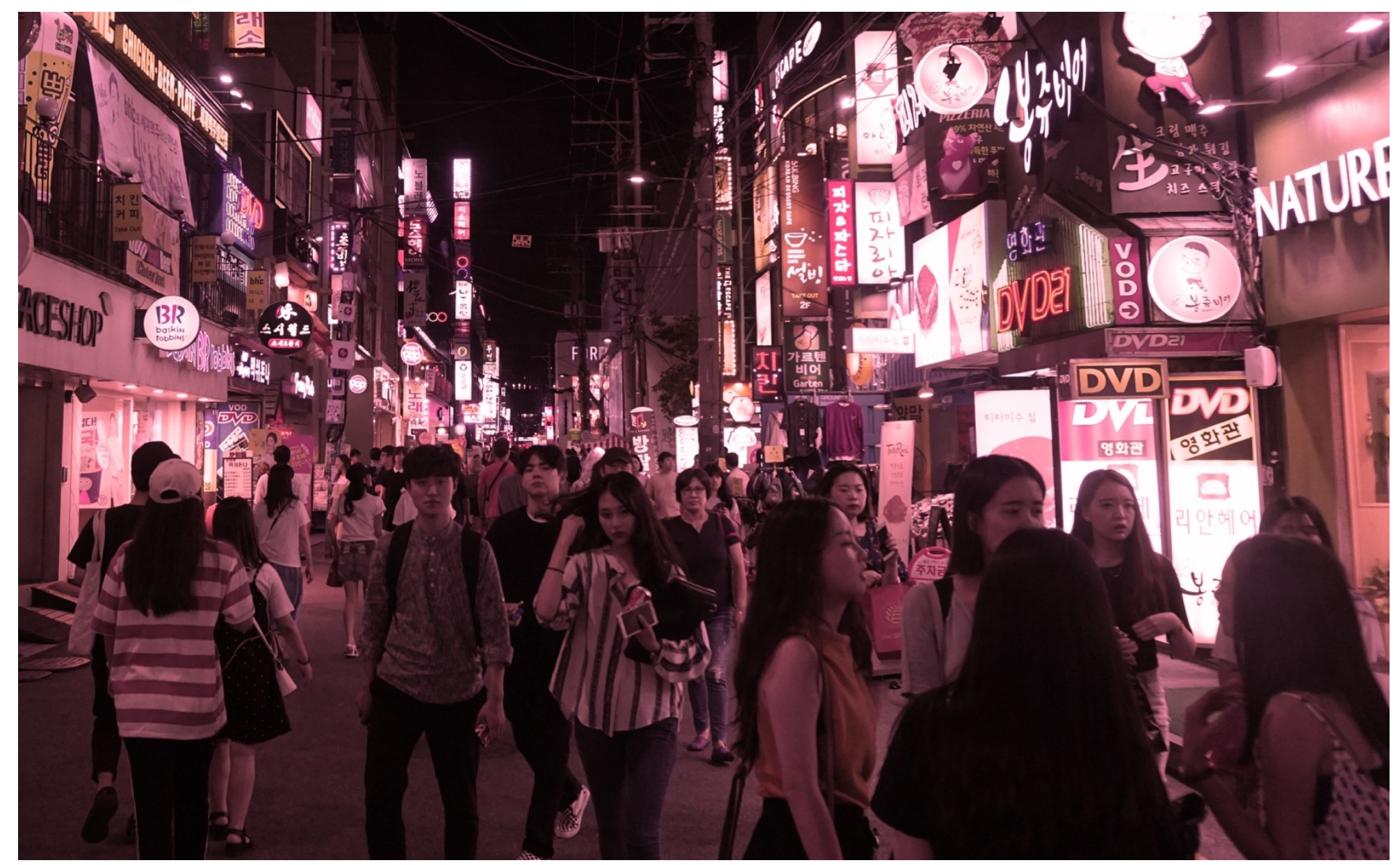

Figure 20: 19th August, 2016. Entrance to a DVD Bang in the Neigbourhood of Hongdae. 


\section{+DVD Bang //DVD Room+}

The DVD Bang concept appeared recently, along with the Norae Bang, but with a much more powerful negative sexual image. Young Koreans live in their parents' house until they decide to get married, which means that they may not be able to get the privacy they want until they are more or less 30 years old. ${ }^{28}$

In 2012, there were 50 DVD Bangs distributed throughout the city of Seoul. ${ }^{29}$ This type of establishment can usually be found in university areas, or areas currently transited by young people. They can also be found on the second or third floor of multi-complex buildings.

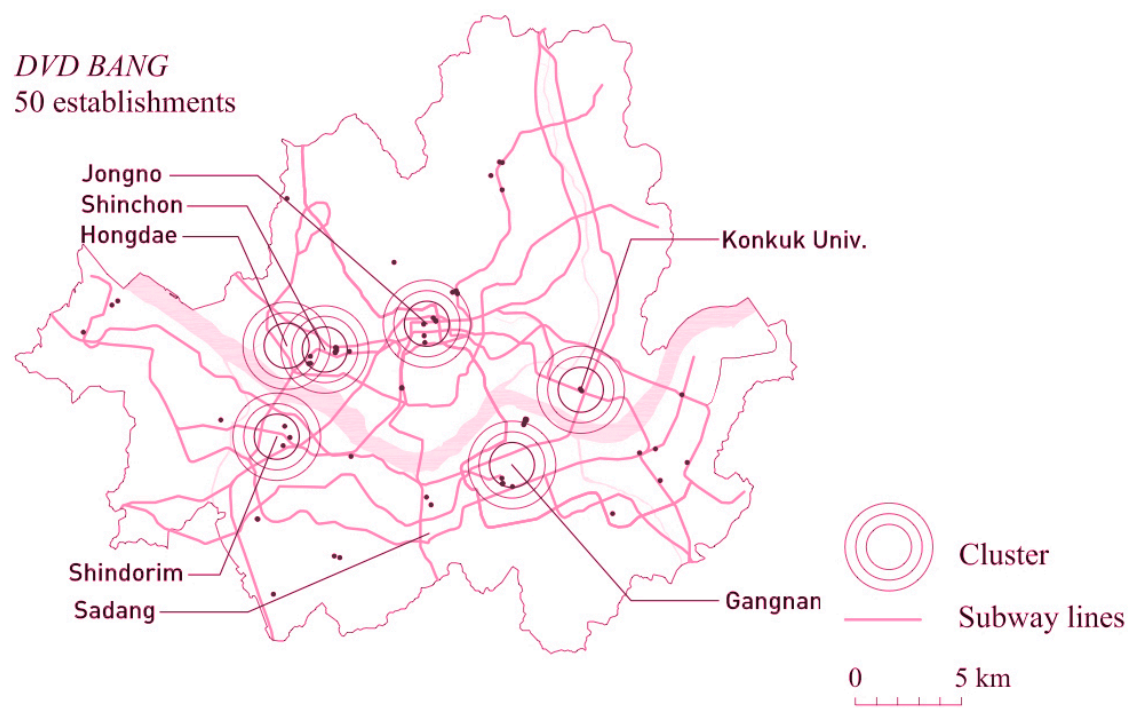

Figure 21: Distribution of DVD Bangs in the city of Seoul, based on Google Maps databases in 2012. Source: Choe, Almazán, y Bennett, «The extended home: Dividual space and liminal domesticity in Tokyo and Seoul».

\footnotetext{
28 Choe, Almazán, y Bennett, «The extended home: Dividual space and liminal domesticity in Tokyo and Seoul».

${ }^{29}$ Ibid.
} 
1. It consists of a private room for two or four people, usually equipped with a sofa bed and a projector to watch movies. //

2. These rooms are rented for the duration of the film that has been chosen to be projected. //

3. The low cost and facilities of this establishment attracts a wide range of young couples, who want to find in DVD Bangs privacy they need, for a much lower price than they could find in a motel. //

4. The rooms cannot be locked with latches or keys, but even so, privacy in this space remains unchanged, since nobody will have the audacity to open the door. //

5. In addition, all rooms have curtains in case of having window doors. // 


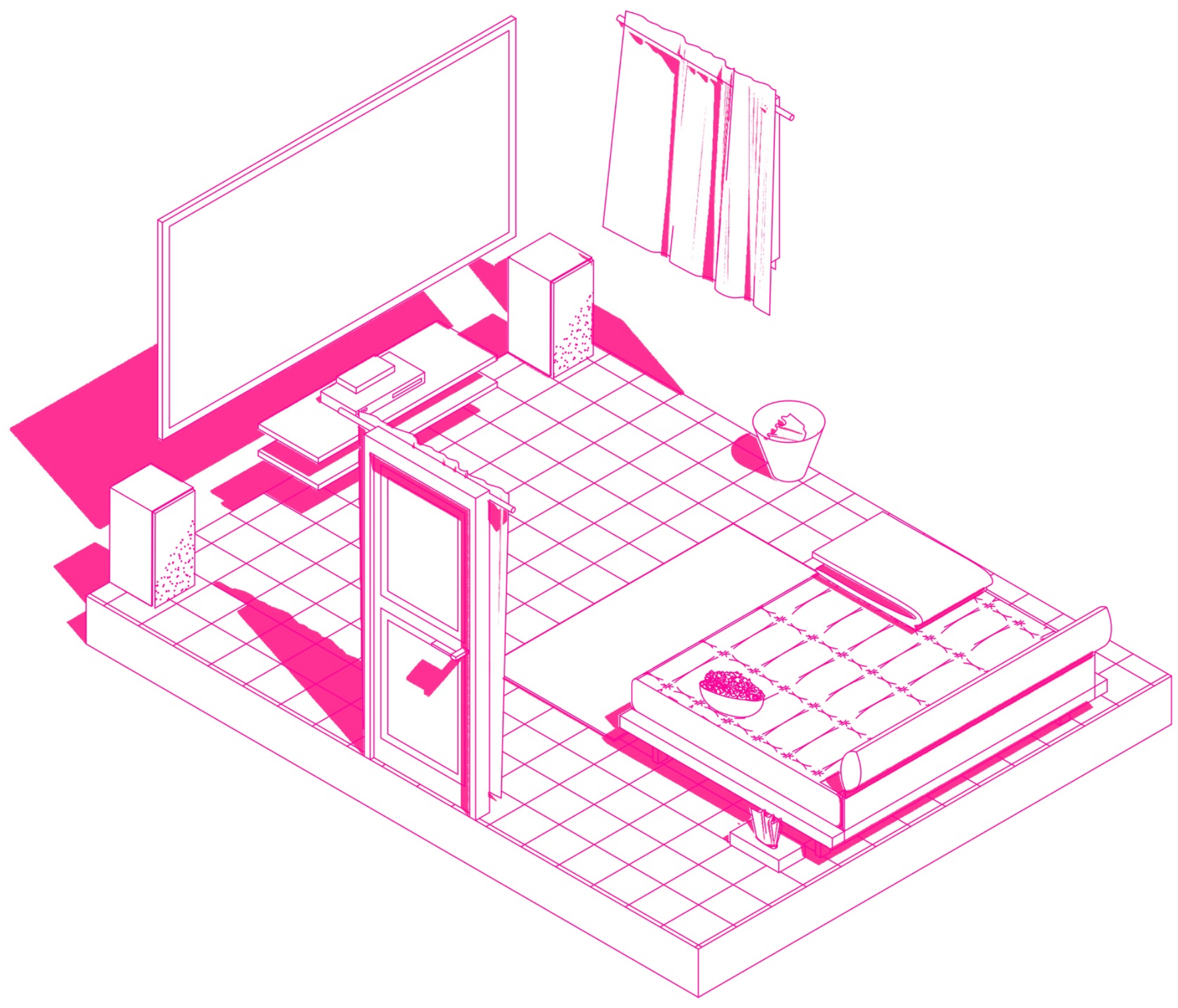

Figure 22: Common DVD Bang. 
1. Due to the sexual prejudice these places have, couples take care of their discretion, since for Korean society it is frowned upon to enter to watch a movie as a couple. //

2. The film is chosen at the reception, which resembles the socalled video clubs, where all the titles they have are displayed in different exhibitors. //

3. The treatment at reception and contact with staff is minimal and brief, in order to help maintain discretion. //

4. The reception usually gives service of snacks, popcorn and drinks through vending machines. //

5. The rental price of the film ranges between 8 and 12 Euros. It may vary, depending on the duration of it. //

6. After the choice of the film and the payment of it, the couple enters the DVD Bang. // 


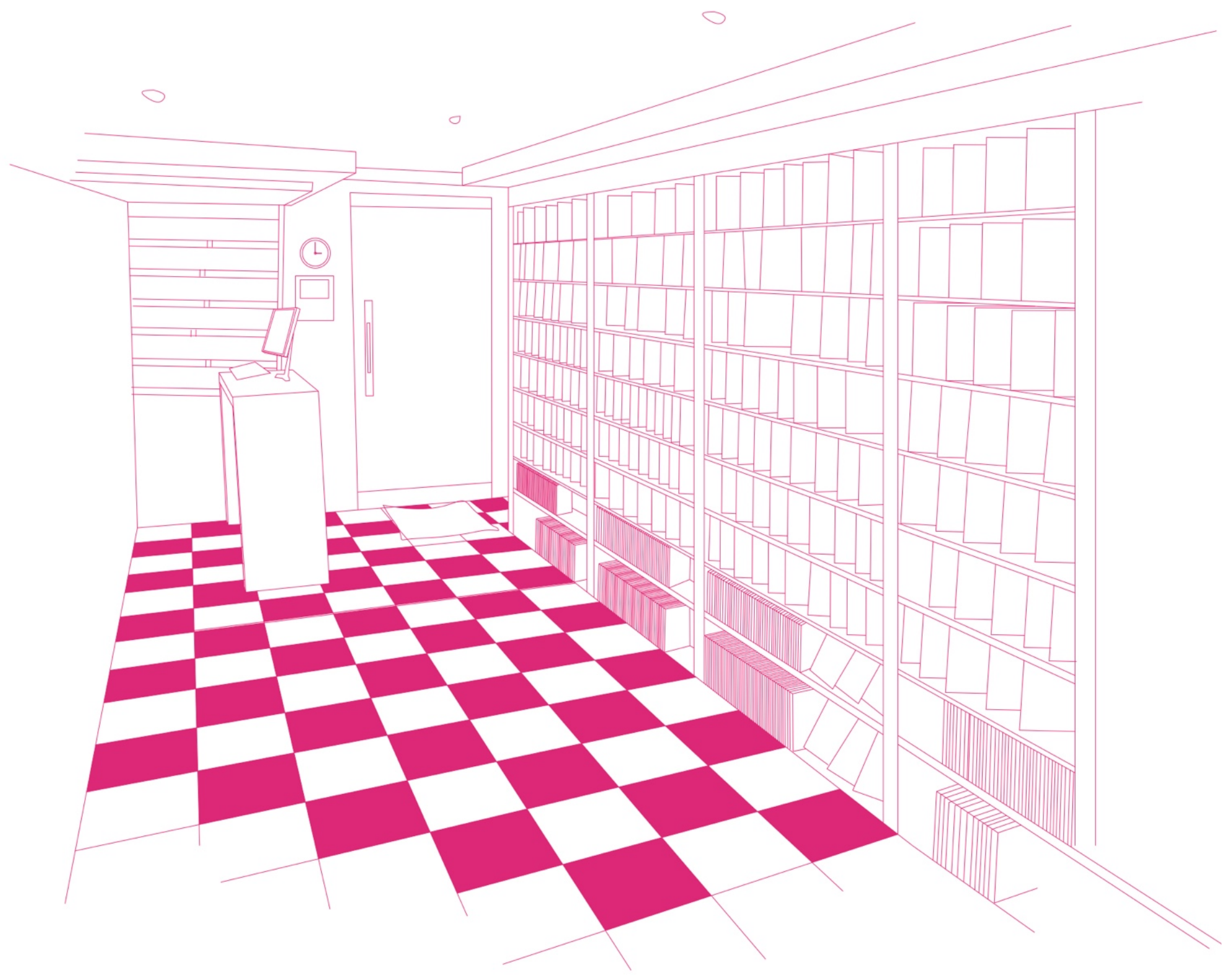

Figure 23: Reception room of a DVD Bang. 
- GUARANTEED DISCRETION -

- SOCIAL PRESSURE -

- DUBIOUS CLEANING -

- CONTROLLED TIME -

- SCARCE COMFORT -

- INSURED PRIVACY -

- FOOD AND DRINK SERVICE - 


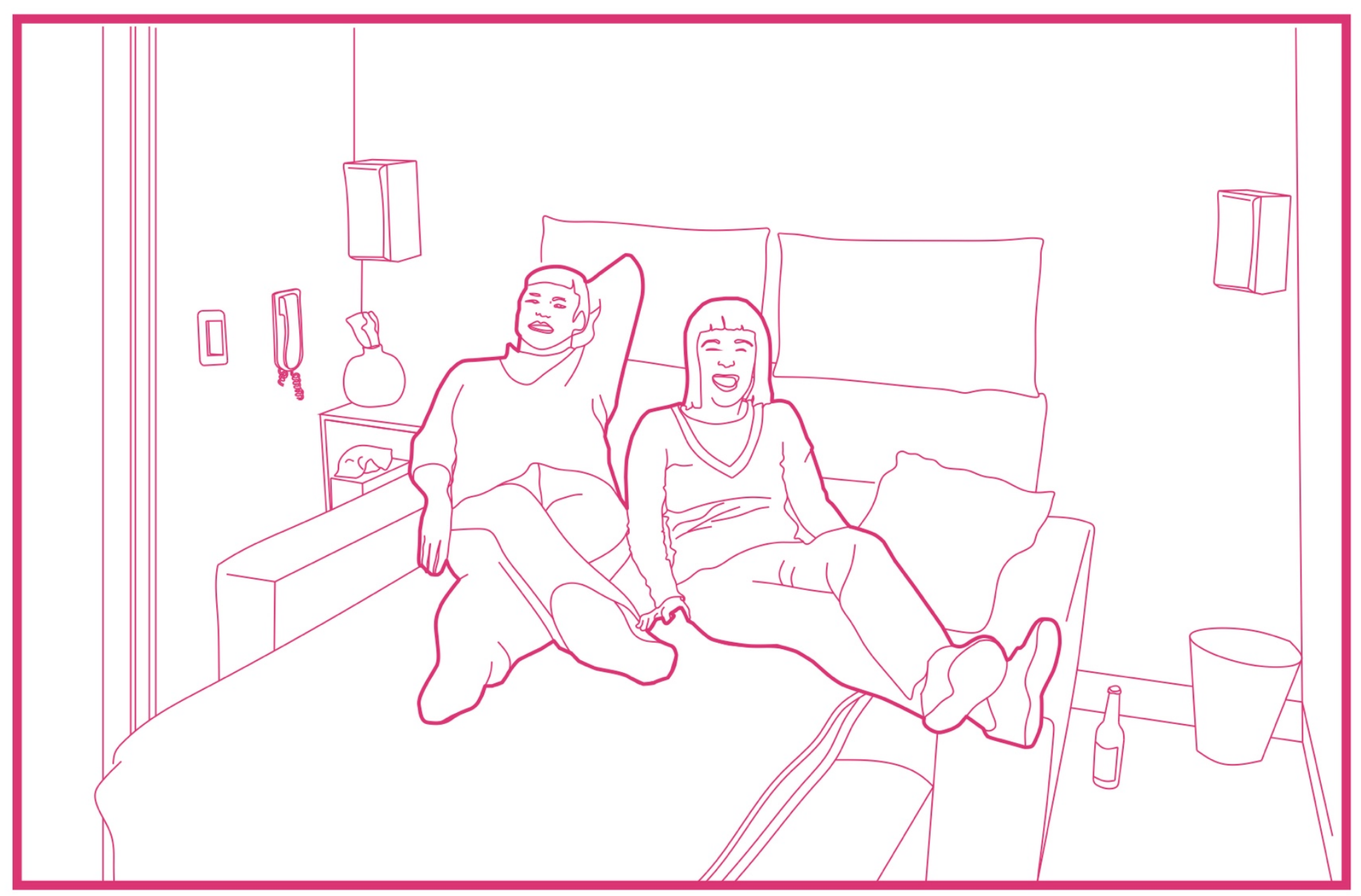

Figure 24: Battlefield for the user of a DVD Bang. 
Among the user profiles are the students, who simply look for this type of space where they can spend time in privacy, take a nap or fall asleep while watching a movie.

It can also be used to watch pornography, which is censored on the internet by the Korean government.

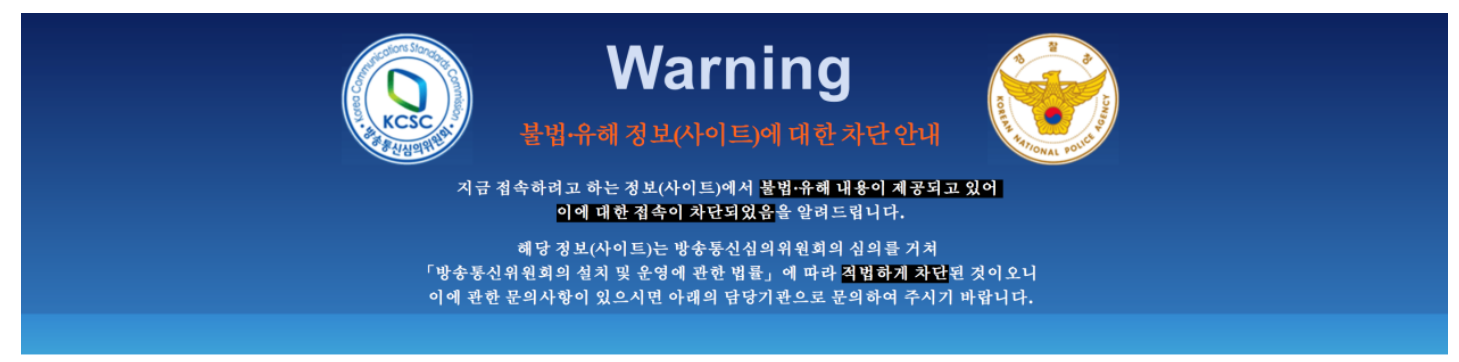

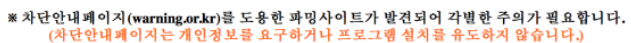

\begin{tabular}{|c|c|c|}
\hline 사이트분야 & 담당기관 & 전화번호 \\
\hline \multirow{2}{*}{ 불법 도박 } & 사이버 경찰쳥 & $1566-0112$ \\
\hline & 사행산업통합감톡위원회 & (02)3704-0538 \\
\hline \multirow[b]{2}{*}{ 불법 체육진홍투표견 푠매 } & 사행 산업통합감독위원화 & (02)3704-0538 \\
\hline & 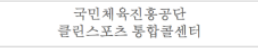 & 1899-1119 \\
\hline \multirow{2}{*}{ 블볍 숭자투표련 구매대행 } & 국민체육진홍공탄 경륜사업본부 & (02)2067-5813 \\
\hline & 국민체육진홍공탄 경정사업본부 & (031)790-8531 \\
\hline 불법 마권 구매대행 & 한국마사혀 & $080-8282-112$ \\
\hline 불법 의약품 푠매 & 식품의약품안전처 의약품콴리파 & (043)719-2657 \\
\hline 블법 의약외품 푠매 및 허위과대푱고 & 식품의약품안전처 의약외품정 책과 & (043)719-3706 \\
\hline 블법 식품 푠매 및 허위과대푱고 & 식품의약품안전처 식품안전퐌리퐈 & (043)719-2058 \\
\hline 블밥 건강기능식품 팜매 및 허위파대푱고 & 식품의약품안전처 건강기능식품정 짹과 & (043)719-2458 \\
\hline 불법 화장픔 푬매 및 허위과대평고 & 식품의약품안전처 화장품정색과 & (043)719-3407 \\
\hline 불법 의료기기 푬매 & 식픔의약품안전처 의료기기콴리과 & (043)719-3808 \\
\hline
\end{tabular}

Figure 25: Censorship of pornography by the Korean government. 

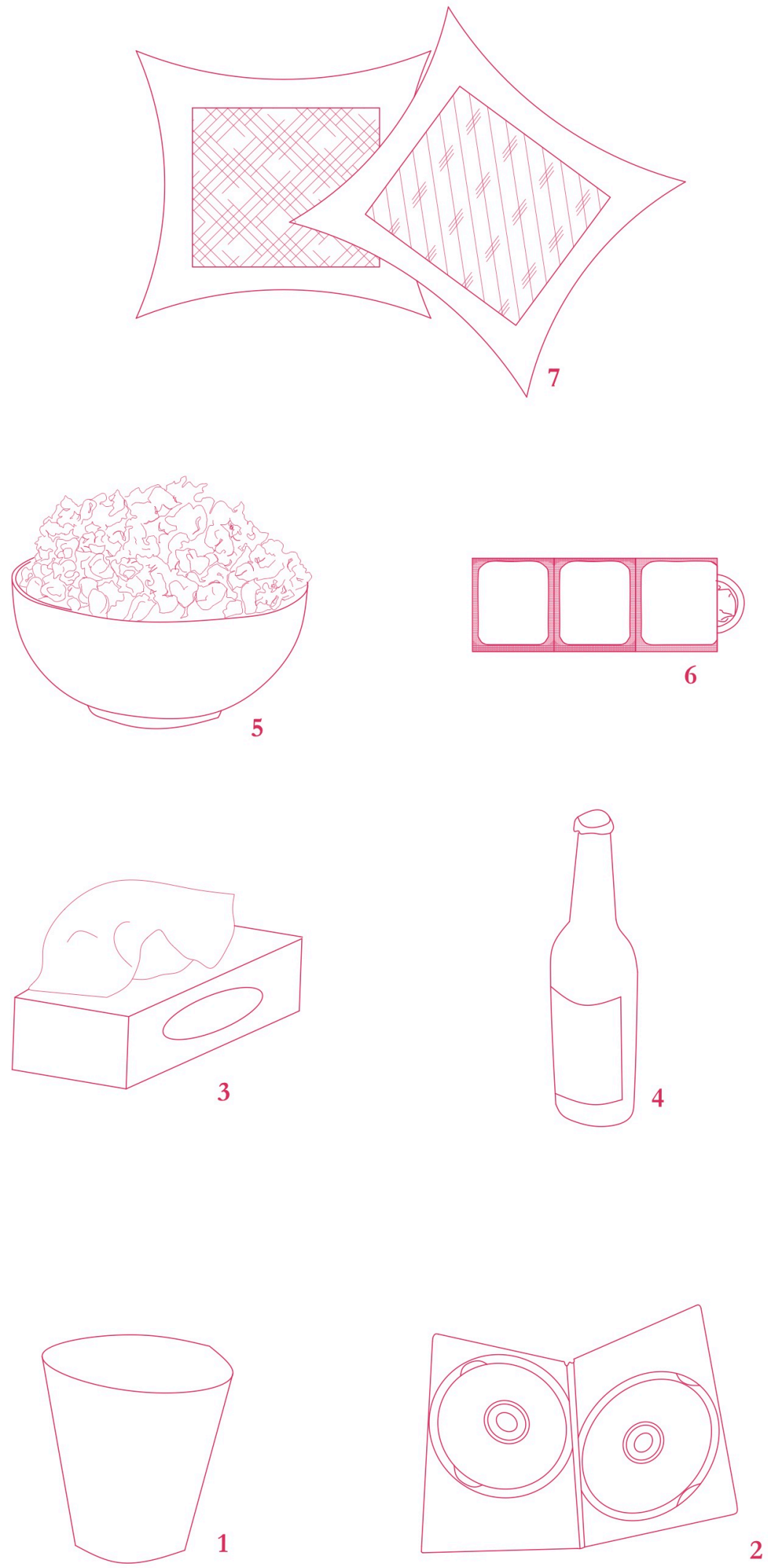

1. Wastebasket//2. Dvd// 3. Tissue box// 4. Beer or soda from vending machine//5. Freshly made pop-corn bowl// 6 . Prophylactic// 7. Pillows// 


\begin{tabular}{|c|c|c|c|c|}
\hline & $\$$ & & WHEN? & (D) (D) \\
\hline CINEMA & $\begin{array}{c}9.000 \# / \text { person } \\
7,2 €\end{array}$ & Duration of the film & 16:00pm - 1:00am & $\begin{array}{l}\text { Privacy not } \\
\text { insured }\end{array}$ \\
\hline $\begin{array}{l}\text { NeTFliX } \\
\text { AT HOME }\end{array}$ & $\begin{array}{c}10.000 \text { \# } \\
7,99 €\end{array}$ & For a month & $\begin{array}{c}\text { When there is no one } \\
\text { at home, or in your } \\
\text { prívate room }\end{array}$ & $\begin{array}{l}\text { Privacy not } \\
\text { insured }\end{array}$ \\
\hline DVDBANG & $\begin{array}{c}10.000 \# \\
8 €\end{array}$ & Duration of the film & 24 hours & $\begin{array}{l}\text { Absolute } \\
\text { privacy }\end{array}$ \\
\hline
\end{tabular}



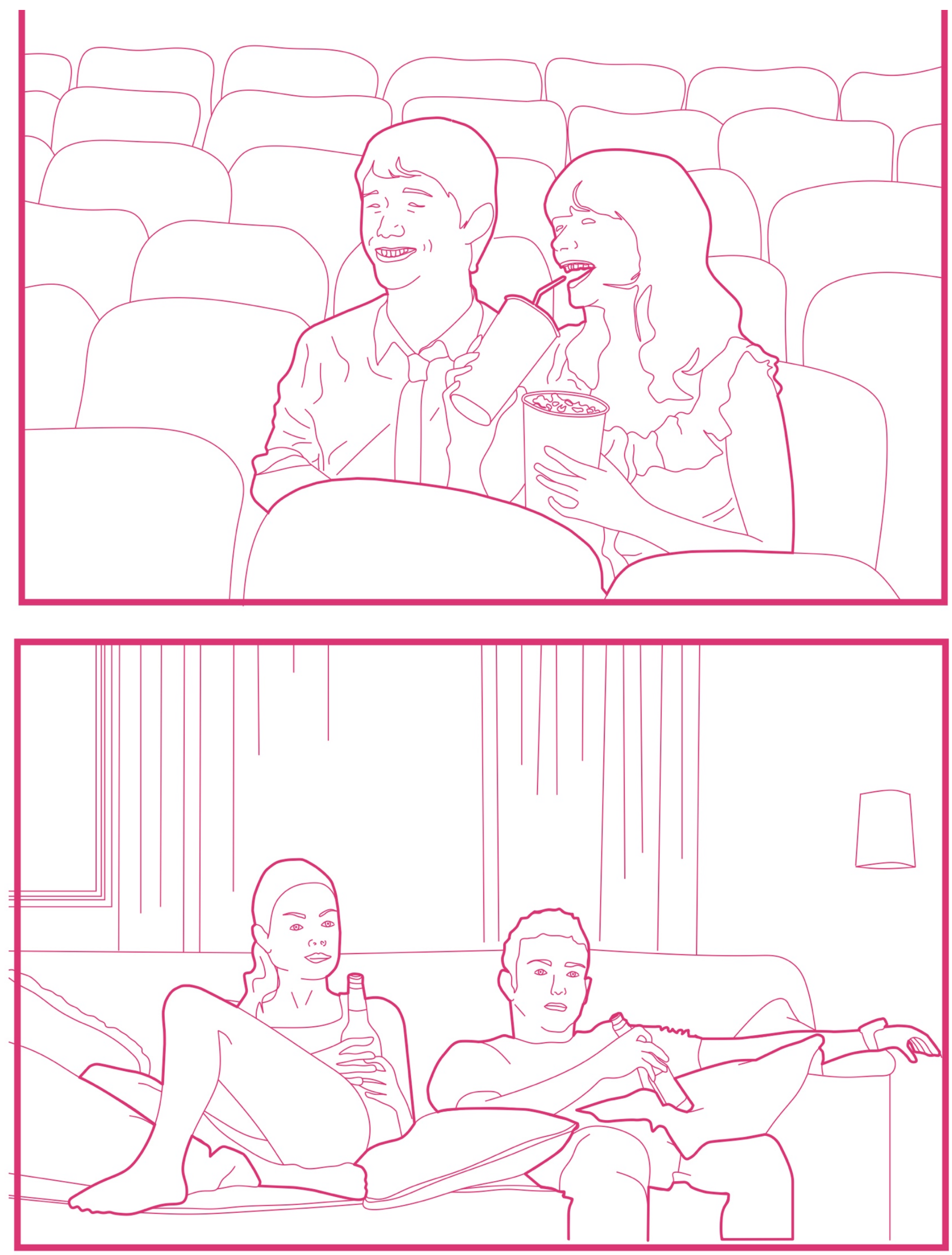


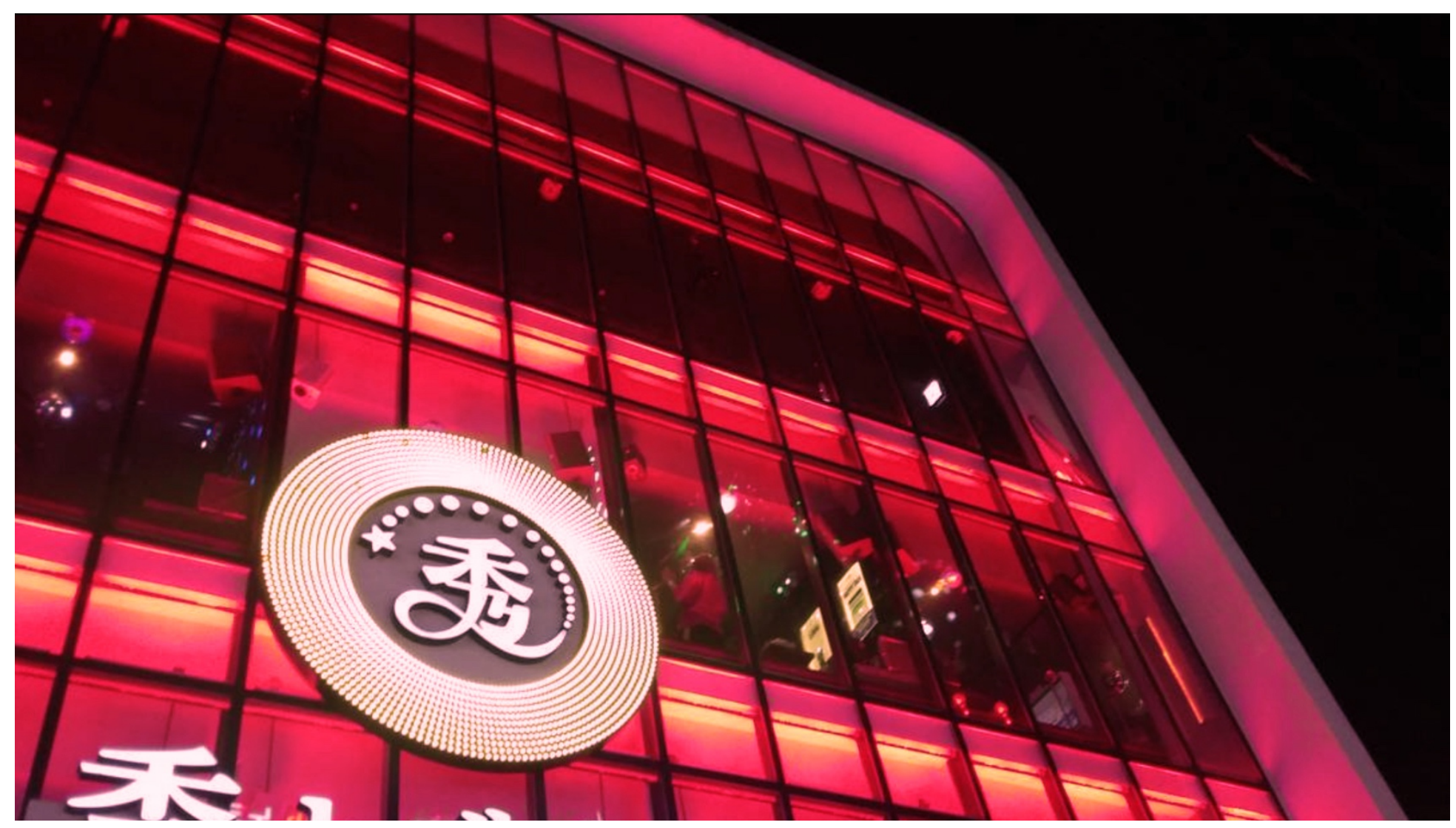

Figure 29: 4th June, 2017. Facade of one of Hongdae's most famous Norae Bang. 


\section{+ Norae Bang // Karaoke Box +}

Karaoke was invented in 1970 in Kobe, Japan. Soon, it ; spread throughout the rest of Japan and the world. In 2012, there were approximately 1375 Norae Bangs scattered around the city of Seoul.. ${ }^{30}$ Karaoke is not only popular in South Korea, but also in other Asian countries such as Japan, Hong Kong, Taiwan, Singapore and much of China.

This type of establishment can be found almost everywhere in the city, but above, all in nightlife and leisure districts such as Hongdae, Gangnam and Apgujeong. They are usually found in the underground floor of multi-complex buildings.

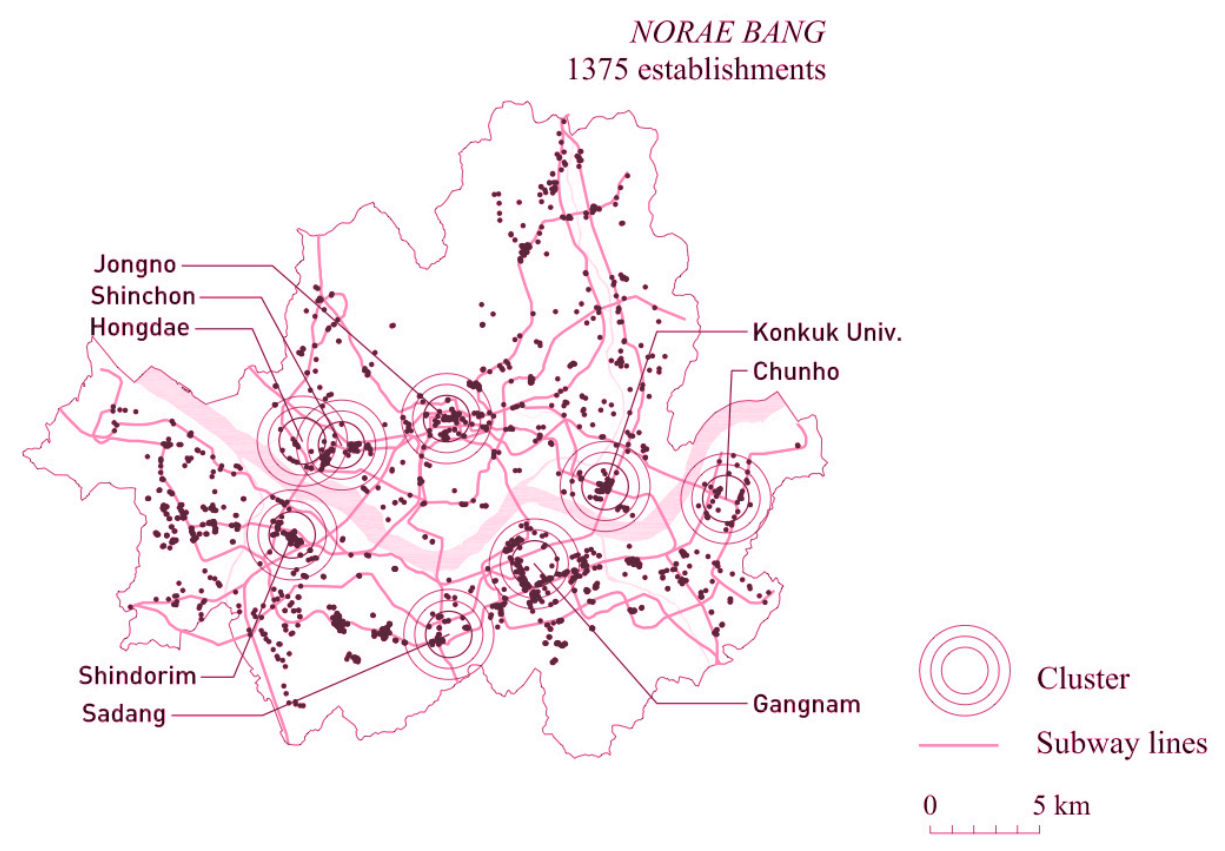

Figure 30: Distribution of the Norae Bangs in the City of Seoul, based on the Google Maps databases in 2012. Source: Choe, Almazán, y Bennett, «The extended home: Dividual space and liminal domesticity in Tokyo and Seoul».

${ }^{30}$ Ibid. 
1. It consists of private rooms of different sizes for four, six or ten people, which contain all the necessary equipment of karaoke to sing and dance. //

2. Currently, it does not only have a karaoke team, but also includes lighting equipment, dolby effects, instruments, a dance bar... //

3. There are special rooms for a larger number of people. //

4. These rooms are rented per hour, but if there are no people waiting, the renting time can be unlimited. //

5. The price per hour costs around 16 Euros, but it may vary depending on the type of room. //

6. The rooms are not locked with latches or keys, but even so, the privacy and privacy in this space remains unchanged, since no one will have the audacity to open the door. // 


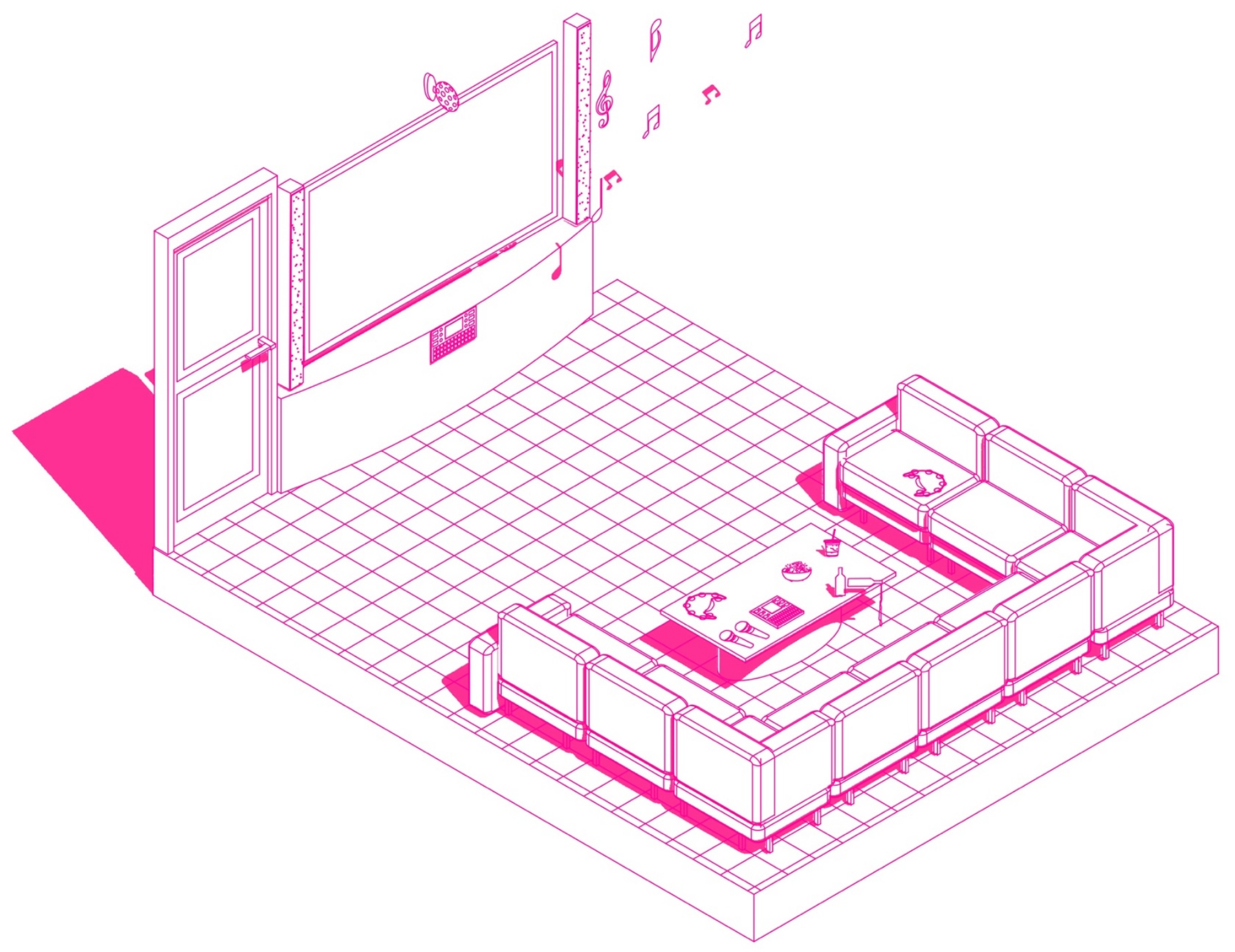

Figure 31: Common Norae Bang. 
In the origins, the user profile of Norae Bang consisted on working men with paid companions, which at the present time has been spreading in society. Women workers, housewives, high school and university students make frequent use of them. ${ }^{31}$

Karaoke is a national obsession, and in spite of that, it is not considered a very public activity. This reflects, in a way, the culture, and unlike the western karaokes, in the Norae Bang, customers do not have to sing in a room full of strangers, but these rooms give the necessary privacy, creating an atmosphere of intimacy for the client so that they can enjoy more, singing to whoever they want or with whomever they want.

In recent years, there has been public concern about crime and sexual practice in these rooms, since during the rental of the room, no one enters the service neither controls what happens inside. This concern has given rise to regulations on the entry of children under 18 after 23.00h. ${ }^{32}$

\footnotetext{
31 Ibid.
}

32 Ibid. 

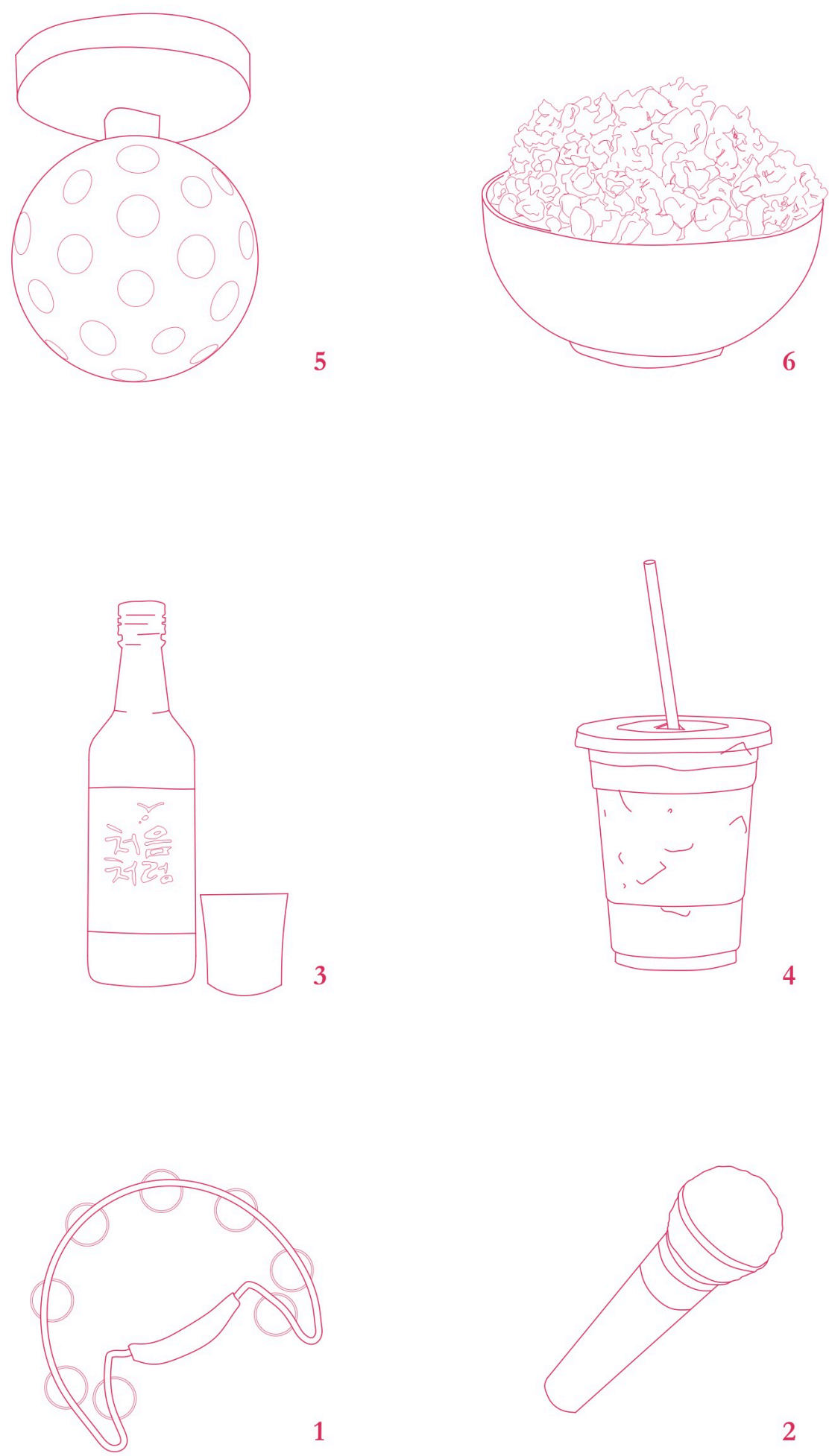

2

1. Tambourine//2. Microphone// 3. Soju + Glass// 4. Glass with ice to mix soju with other drink// 5. Gyratory ball of colours lights // 6. Bowl with popcorn or chips// 


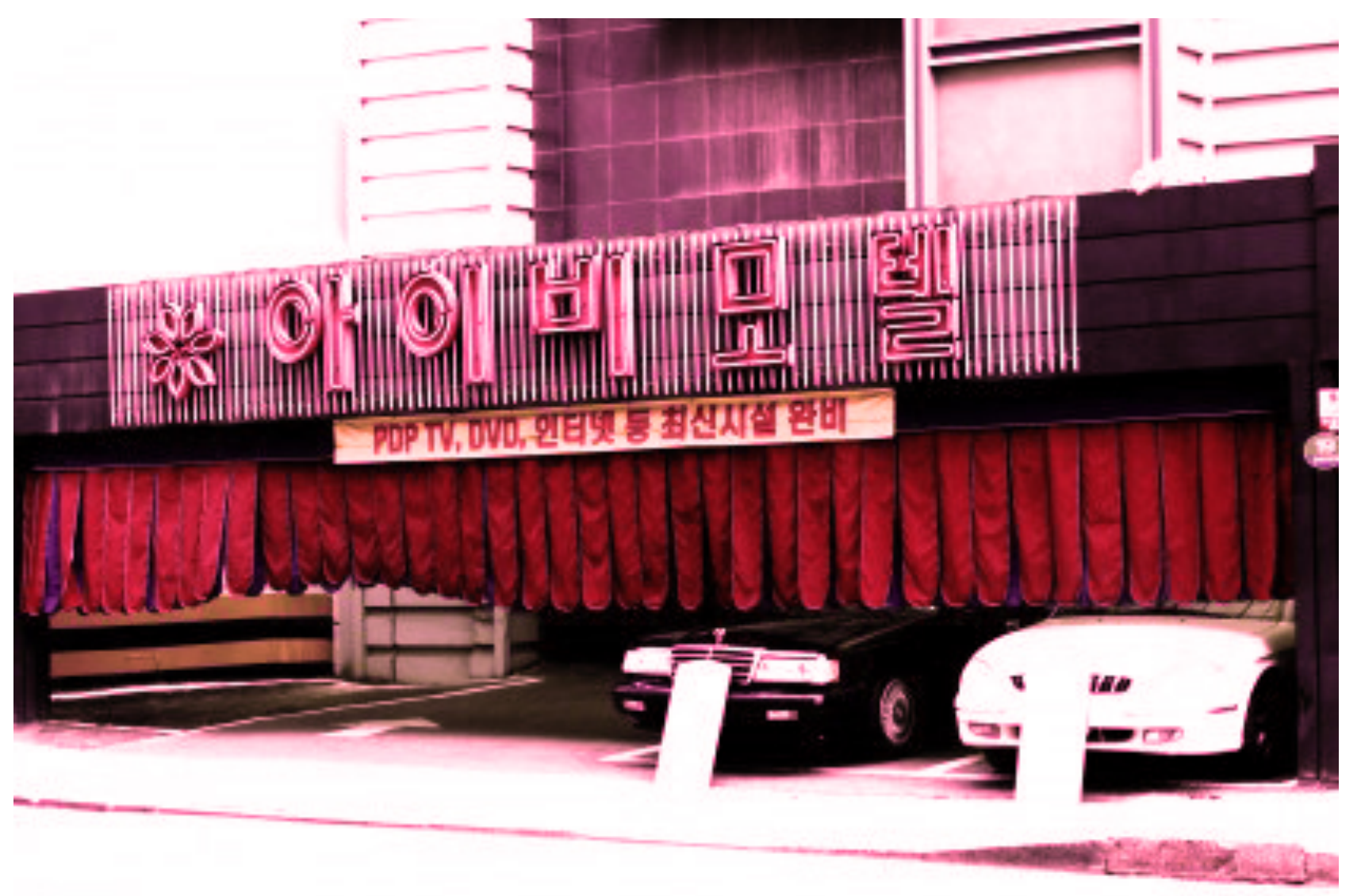

Figure 33: Common motel entrance. 


\section{+ Motel// Love Hotel +}

The motels originated in Japan, during the Edo deaichaya period, and consisted of tea rooms usually used by prostitutes and their customers. After the Second World War, lodgings were originally adapted with a few rooms maintained and operated by families who used them as spare rooms. These rooms were called "tsurekomi yado", translated as "bring your own interior".

In the year 1958, prostitution was abolished, so the trade and the guild of prostitution became a clandestine activity, and there was a boom of "tsurekomi yado". In the sixties, the "tsurekomi vado" cleaned their image and became business hotels, serving working men, as well as love hotels, serving couples.

In 2012, there were approximately 851 Motels scattered around the city of Seoul. ${ }^{33}$ As can be seen, the motels are located on the outskirts of the city and in the economic or university areas.

MOTEL

851 establishments

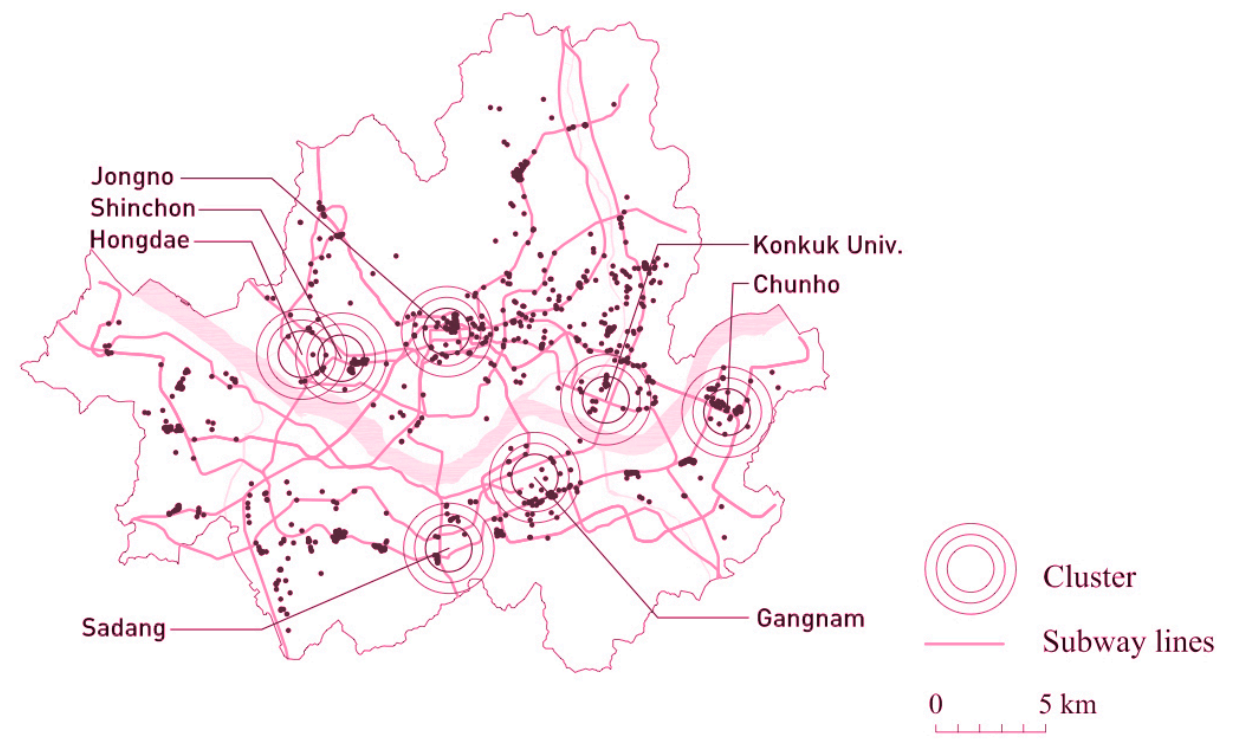

Figure 3: Distribution of motels in the city of Seoul, based on the Google Maps databases in 2012.

Source: Choe, Almazán, y Bennett, «The extended home: Dividual space and liminal domesticity in Tokyo and Seoul».

33 Ibid. 
1. It consists of a private room rented either per hour or per night. //

2. Currently, it does not only have a bed and a bathroom, but, also generally a plasma TV, a computer, a refrigerator, etc. And, in some cases, special lighting, a Jacuzzi, spa, karaoke, etc. //

3. The price for the basic room can range from 40 Euros per night, but there are special rates for hours during the day, used mainly by students of by office workers.

4. The motels underwent a transition from degradation to basically becoming cheap accommodation for sex, thanks to marketing focused on young consumers which allowed them to relax from social pressure environments, and at the same time, the rooms had a domestic character. //

5. The motels have improved their image over time, and there are even different types of motels: theme motels, boutique motels, officetels, etc. //

6. The use of these rooms is common nowadays by couples before marriage, and, a posteriori, as an escape from routine. // 


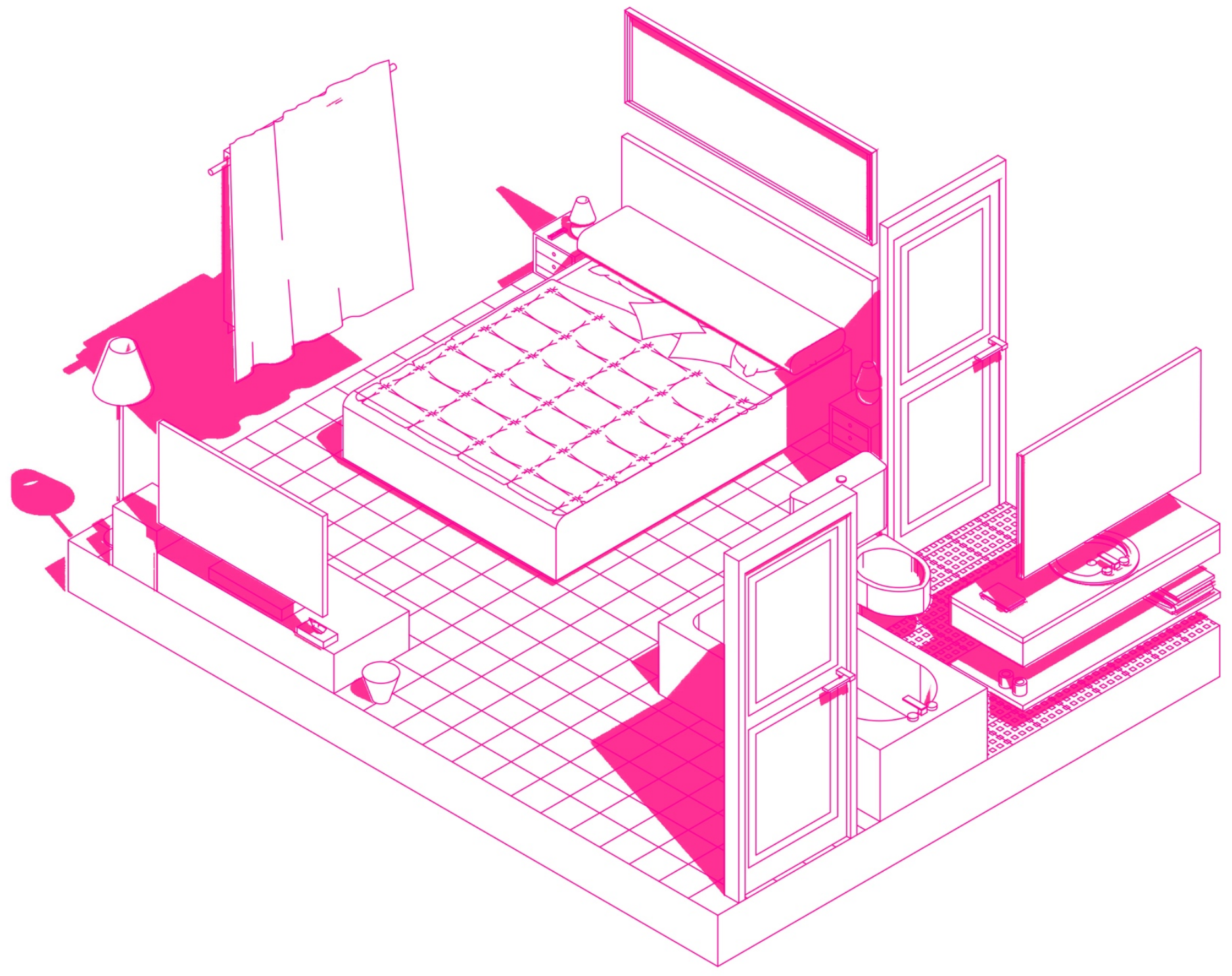

Figure 35: Common motel room. 
1. There are great measures of discretion and anonymity, given that room reservations require no identification, and the payment can be made in cash, so that the payment does not appear in the current account expenses. //

2. The hotel can be entered by car, so that entrance is sufficiently protected. In addition, it should be noted that all cars in Corea, or the vast majority of them, have tinted windows. //

3. The contact with the reception is minimal, and can even be null, since the Check-In can be done by telephone. //

4. All this anonymity and discretion is necessary, given the high degree of adultery that Korean society has, due to the late legalization of divorce. //

5. December the $25^{\text {th }}$ is established by Korean couples as the day of the motels, and that day rates usually rise. // 


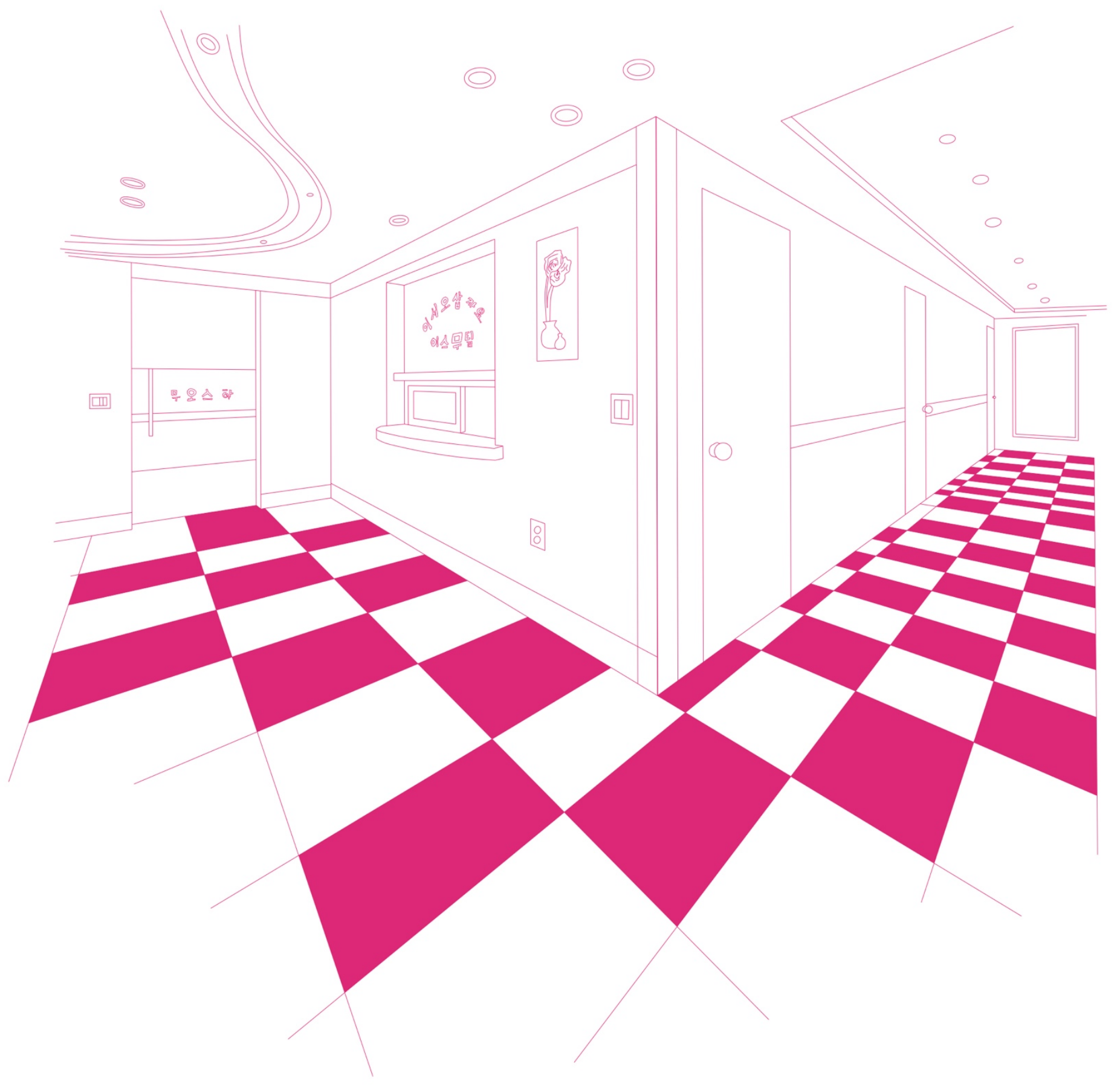

Figura 36: Common motel reception. 


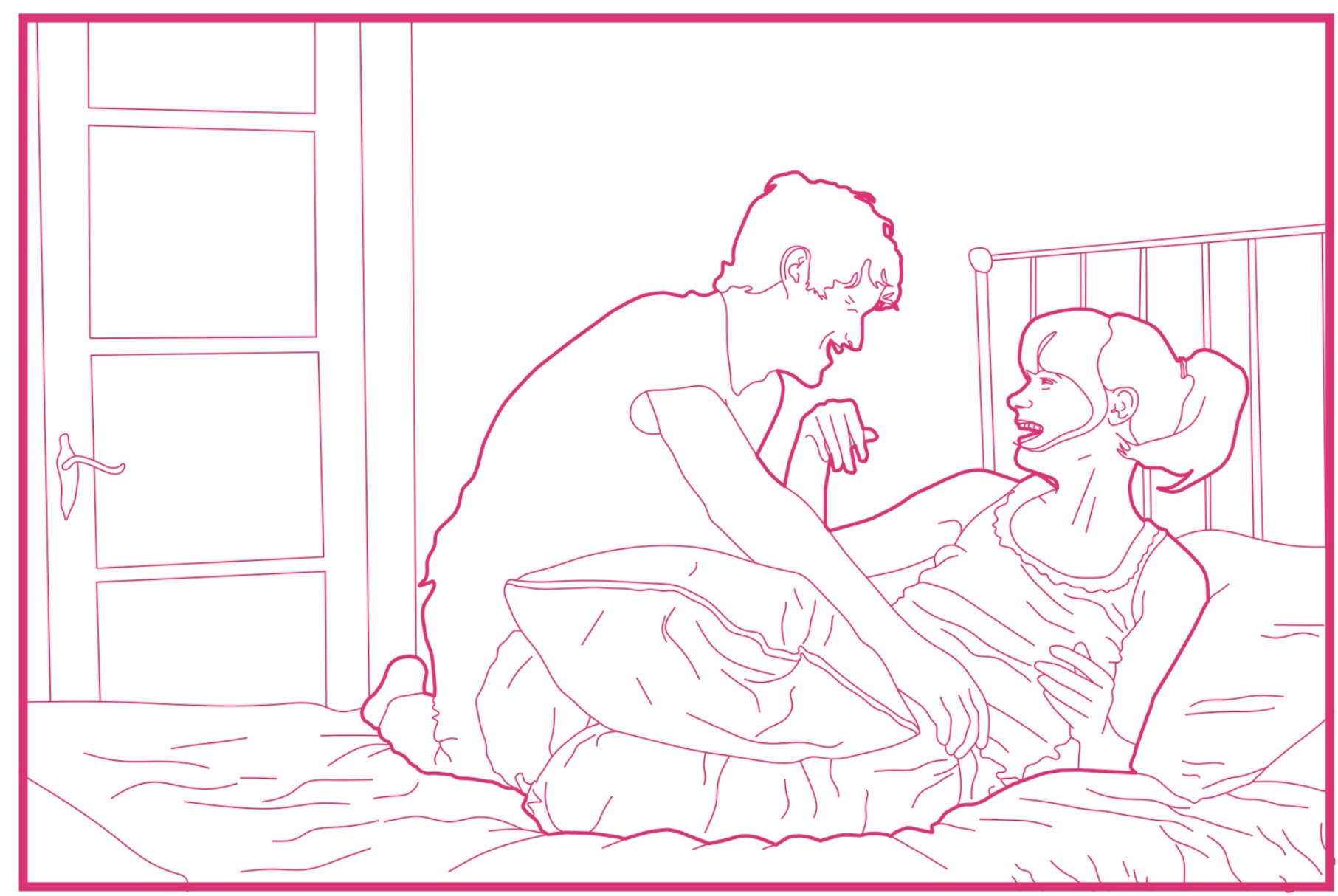

Figure 37: Battlefield in a Motel.

(Right) Figure 38: Kit received by the user at the reception of the motel. 

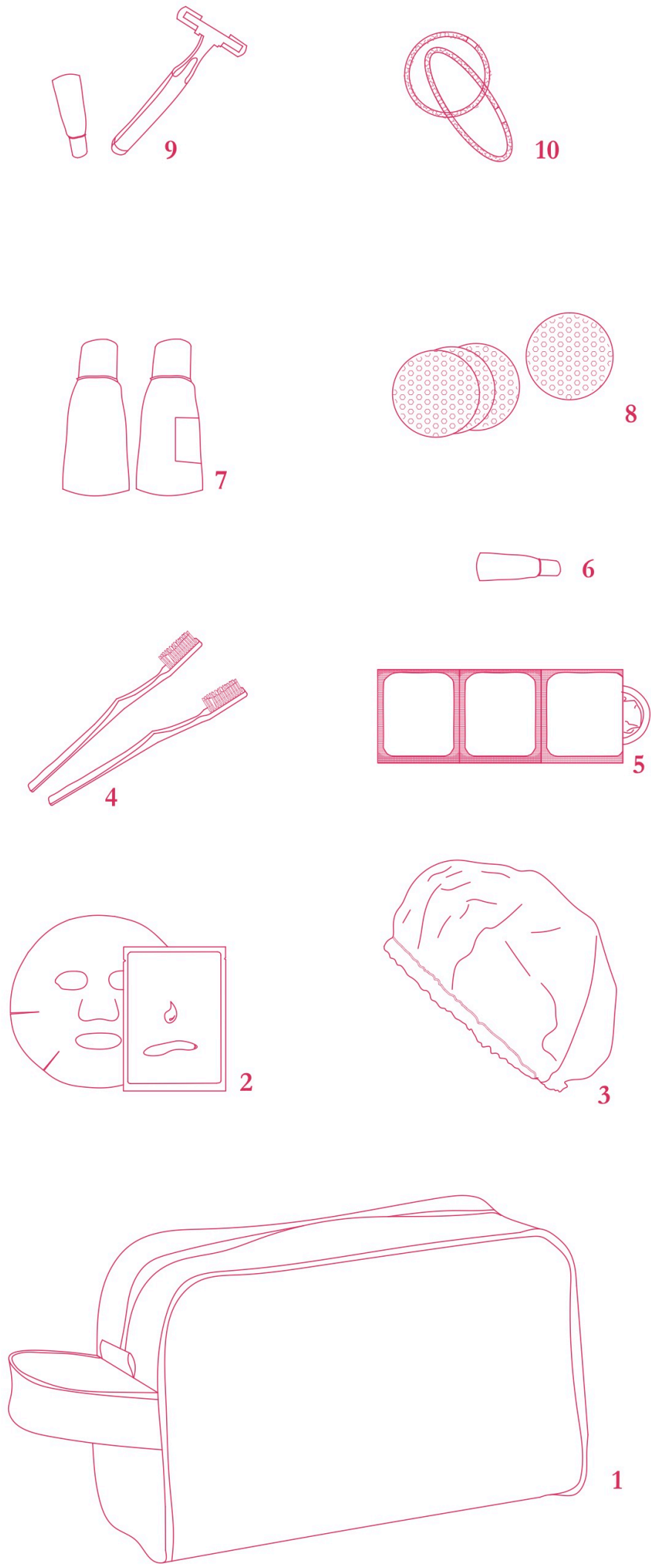

1. Vanity case// 2. Face mask// 3. Shower cap// 4. Toothbrush// 5. Prophylactic// 6. Toothpaste// 7. Shower gel and shampoo// 8. Cleansing pads// 9. Shaving kit // 10. Scrunchies// 


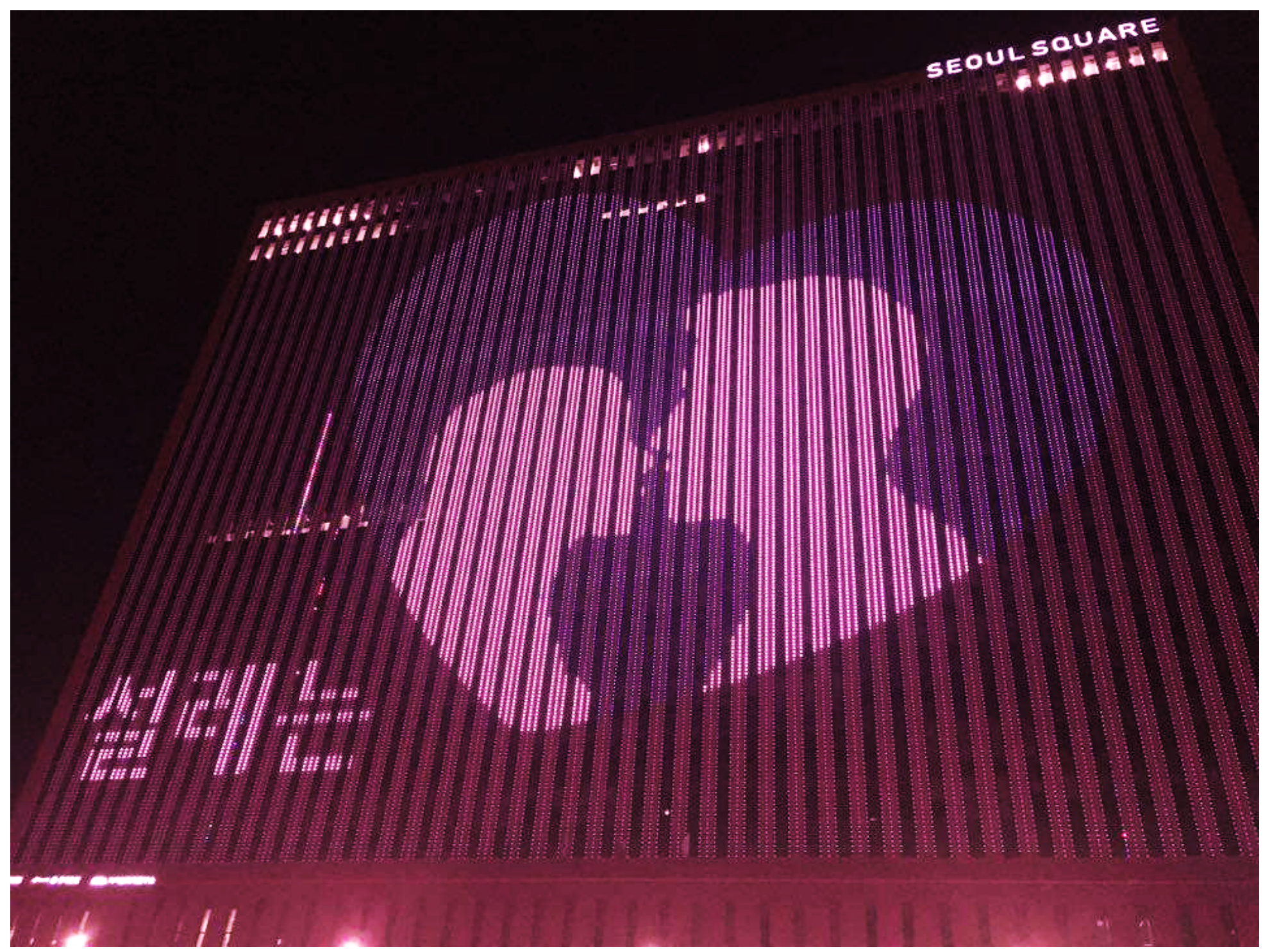




\section{Conclusions.}

\section{THE CITY IS CONNECTIONS.}

South Korea is shown to the world, or whoever visits it, as a rosy world for Korean couples of apparent perfectionism. It is impossible to think of going down the street without seeing couples walking around with their girls holding their bags, or going to a coffee shop and not feeling surrounded by couples spending an afternoon together: perhaps doing their homework, where the girl seems constantly worried about her image and the boy worried that she feels good.

It is impossible to go for a walk around the city and not find technologies, infrastructures and architectures for this model of heterosexual couple of the 21st century, prepared for a perfect "selfie" spending some time together.

The heterosexual couple is implanted as the unique model. Homosexual love, like feminism, has been understood as a threat to national masculinity, and narratives that affect these forms of sexuality have been silenced in favor of the image of Korea as the most Confucian country on Earth, with a solid tradition of patriarchy and sexual property.

Korean notions are, as has been said along this dissertation, deeply shaped by Confucianism, and the concept of "good wife, wise mother" and the complementary role of husband and father as a patriarch contributed from the very beginnings to the construction of a binary gender system, even before the colonial era. This system could have potentially influenced the decision to place their same-sex relationships in a male-female binary.

Consequently, the Korean woman is 'subject' to the 'obligation' to procreate a male child in order to safeguard patrilineal purity; the male child is the one who assumes the duty of performing the cult of the ancestors, and on him depends the maintenance of his elderly parents, as a way of preserving family tradition and honor.

During the colonial era, Christianity flourished as an alternative to Korean shamanism and Buddhism, introduced through different missionary activities that were given in the country. This Christianity is still present and today, the love for the same sex and eroticism remains socially unacceptable and is considered as a threat to national pride. However, the city has, as we have seen, different technologies and infrastructures for the necessary privacy for both eroticism and sexual relations. 


\section{References}

Choe, Sanki, Jorge Almazán, and Katherine Bennett. «The extended home: Dividual space and liminal domesticity in Tokyo and Seoul». URBAN DESIGN International 21, n. 4 (November 1st, 2016): 298-316. doi:10.1057/udi.2016.10.

Choi, E. J. «The Body in Packaging Culture: Researching Cosmetic Surgery within Korea's Neo-Confucian Culture». Master thesis. September 21st, 2015. http://dspace.library.uu.nl/handle/1874/320457.

Choi, Jaz Hee-jeong. «The city of connections: urban social networking in Seoul». ARC Centre of Excellence for Creative Industries and Innovation; Creative Industries Faculty MindTrek: 12th international conference on Entertainment and media in the ubiquitous era (October $\left.6^{\text {th }}, 2008\right): 189-93$. doi:http://doi.acm.org/10.1145/1457199.1457241.

Choi, Jaz Hee-jeong, y Adam Greenfield. «To connect and flow in Seoul: Ubiquitous technologies, urban infrastructure and everyday life in the contemporary Korean city». Edited by Marcus Foth. Handbook of research on urban informatics: the practice and promise of the real-time city, 2009, 21-36.

Choi, Jaz Hee-Jeong, y Adam Greenfield. «To Connect and Flow in Seoul: Ubiquitous Technologies, Urban Infrastructure and Everyday Life in the Contemporary Korean City». Edited by Marcus Foth. Handbook of Research on Urban Informatics: The Practice and Promise of the Real-Time City, 2009, 21-36. doi:10.4018/978-1-60566-152-0.ch002.

Foth, Marcus. From Social Butterfly to Engaged Citizen: Urban Informatics, Social Media, Ubiquitous Computing, and Mobile Technology to Support Citizen Engagement. MIT Press, 2011.

«Gangnam Style, Dissected: The Subversive Message Within South Korea's Music Video Sensation - The Atlantic». Last accessed: September 3 3rd, 2017. https://www.theatlantic.com/international/archive/2012/08/gangnam-styledissected-the-subversive-message-within-south-koreas-music-videosensation/261462/.

Hyun Jeong Min. «New Women and Modern Girls: consuming foreign goods in colonial Seoul». Journal of Historical Research in Marketing 5, n. 4 (November 4th, 2013): 494-520. doi:10.1108/JHRM-01-2013-0004.

Kim, Elaine H., y Chungmoo Choi, eds. Dangerous Women: Gender and Korean Nationalism. 1 edition. New York: Routledge, 1997.

Kim, Jung In. «The birth of urban modernity in Gangnam, Seoul». arq: Architectural Research Quarterly 19, n.o 4 (December, 2015): 369-79. doi:10.1017/S1359135515000615.

Min, Pyong Gap. «Korean “Comfort Women”: The Intersection of Colonial Power, Gender, and Class». Gender and Society 17, n. 6 (2003): 938-57. doi:10.2307/3594678.

Pitarch, Pedro. «Building from controversies». Bartlebooth IV: Las Virtudes, septiembre de 2015.

Song, Jesook. «'A room of one's own’: the meaning of spatial autonomy for unmarried women in neoliberal South Korea». Gender, Place \& Culture 17, n. 2 (1 de abril de 2010): 131 49. doi:10.1080/09663691003600264. 
Varga, Aniko. «National Bodies: The "Comfort Women" Discourse and its Controversies in South Korea». Studies in Ethnicity and Nationalism 9 (s. f.): 287-303. 